\title{
EFFECT OF MOLECULAR WEIGHT ON SECONDARY NEWTONIAN PLATEAU AT HIGH SHEAR RATES FOR LINEAR ISOTACTIC MELT BLOWN POLYPROPYLENES
}

\author{
Jiri Drabek $^{1}$, Martin Zatloukal ${ }^{1, *}$ and Mike Martyn ${ }^{2}$ \\ ${ }^{1}$ Polymer Centre, Faculty of Technology, Tomas Bata University in Zlín, \\ Vavrečkova 275, 76001 Zlín, Czech Republic \\ ${ }^{2}$ IRC in Polymer Engineering, School of Engineering, Design \& Technology, \\ University of Bradford, Bradford BD7 1DP, UK
}

Keywords: High shear rate rheology, secondary Newtonian viscosity, polymer melt, melt blown, isotactic polypropylene, rheological models.

*Corresponding author: mzatloukal@utb.cz 


\begin{abstract}
In this work, three melt blown grades of isotactic linear polypropylenes, with weight average molecular weights between 56250 - $75850 \mathrm{~g} / \mathrm{mol}$, have been characterized at $230{ }^{\circ} \mathrm{C}$ over a very wide shear rate range $\left(10-10^{7} 1 / \mathrm{s}\right)$ by using conventional rotational and twin bore capillary rheometry equipped with novel orifice die design, and by an instrumented capillary nozzle on an injection molding machine. A low shear rate primary Newtonian plateau, a pseudoplastic region and a well developed secondary Newtonian plateau (occurring between $2 \cdot 10^{6}-7 \cdot 10^{6} 1 / \mathrm{s}$ ) were identified for all the polypropylene melts. Considering the typical value of pressure sensitivity coefficient for polypropylene melt, $\beta=20.00 \mathrm{GPa}^{-1}$, and measured flow activation energy at the secondary Newtonian plateau, $\mathrm{E}_{\infty}=25.204 \mathrm{~kJ} / \mathrm{mol}$, it was found that the effect of viscous dissipation and pressure is mutually cancelled, i.e. that the measured viscosity data can be considered as the true material property within the whole applied shear rate range. For the first time, it has been revealed that the secondary Newtonian viscosity, $\eta_{\infty}$, depends linearly on the weight average molecular weight, $M_{w}$, in $\log$-log scale as $\eta_{\infty}=1.19 \cdot 10^{-6} M_{w}{ }^{1.084}$. The observed slope close to 1 between $\eta_{\infty}$ and $M_{w}$ suggests that polymer chains in the melt are disentangled at the secondary Newtonian plateau region. This conclusion is supported by the experimental observation that the high shear rate flow activation energy $E_{\infty}$ for given PP melts is comparable with the flow activation energy of PP like oligomer (squalane, $\mathrm{C}_{30} \mathrm{H}_{62} ; 2,6,10,15,19,23$-hexamethyltetracosane). The measured flow data were fitted by six different viscosity models, from which two, namely Modified Carreau and Quemada models, were suggested here for the first time. It has been found that the accuracy of utilized models to describe the measured data is the highest for the newly suggested models and decreases in the following order: Modified Quemada model, Modified Carreau
\end{abstract}


model, Carreau-Yasuda model, Cross model, Generalized Quemada model and Carreau model.

\section{INTRODUCTION}

Melt blowing is a fabrication process typically used in the production of nonwoven polymer micro-fibers. Low viscosity polymers are extruded through a spinnerette die containing several hundred holes. At the end of the die, an air manifold is located to provide hot and compressed high velocity air, which stretches the melt creating fibers when it leaves the spinnerette (see Figure 1). It has been reported that polymeric nanofibers can also be produced by melt blown technology through, firstly, changing of processing conditions [1], secondly, by the polymer modification [2-3], and finally, by utilizing a special die where orifice diameters, $D$, are very small $(0.064 \mathrm{~mm}-0.125 \mathrm{~mm})$ and length-to-diameter ratio, $L / D$, is very large (20/1-1000/1) [4-6]. Thus, it is possible to produce nanofibers at reasonable rates, and provide melt blown fibers of the same size range as those previously exclusive to the domain of electrospinning technology [3, 6-8].

Polypropylene is the most widely used polymer in the melt blown technology due to its low cost, ease of processing, good mechanical properties, and chemical inertness [9-12]. In order to understand the formation of nanofibers and process stability, it is necessary to know rheological behavior of these polymers. Probably the first researcher to perform a detailed rheological characterization of melt blown PPs was Yizhong Wang [13]. Wang characterized two ExxonMobil Escorene melt blown PPs (MFI of 400 and $1200 \mathrm{~g} / 10 \mathrm{~min}$ ) at $185-240{ }^{\circ} \mathrm{C}$ using an Advanced Rheometric Expansion System (ARES, frequency range 0.1-100 rad/s) and advanced capillary extrusion rheometer covering shear rates in the range 1 to $10^{5} 1 / \mathrm{s}$. Later, Rajkishore Nayak [14] investigated the rheological behaviour of four melt blown PPs (MFI of 100, 300, 1000 and $2000 \mathrm{~g} / 10 \mathrm{~min}$ with $\mathrm{M}_{\mathrm{w}}$ of 100 875, 77 590, 60238 and 55509 
$\mathrm{g} / \mathrm{mol}$ ) between $180-210{ }^{\circ} \mathrm{C}$ utilizing an ARES in dynamic mode and low frequency range $(0.1-100 \mathrm{rad} / \mathrm{s})$. Both authors showed that conventional rheological tools can be used for rheological characterization of very low viscosity melt blown PPs but, such tools are limited in being unable to cover extreme deformation rate range typical for melt blown technology, i.e. $10^{6}-10^{7} 1 / \mathrm{s}[1,15]$, which significantly limits optimization of this process.

There are only a few papers reporting shear viscosity measurements for polymer melts at such high shear rate range utilizing specially designed rheological equipment such as hydraulically powered capillary rheometer [16] or an instrumented injection molding machine $[17,18-20]$. With respect to polyolefins (such as polypropylene, PP, high-density polyethylene, HDPE, and ultra-high-molecular-weight polyethylene, UHMWPE), the following key conclusions have been found.

Firstly, HDPE and UHMWPE exhibit a Newtonian behaviour between about $3 \cdot 10^{6}$ $5 \cdot 10^{6} 1 / \mathrm{s}[16]$ whereas at higher shear rates, the second shear thinning region was observed. In this flow regime, shear viscosity decreases with the shear rate mainly due to polymer chain scission, which was confirmed via monitoring of weight average molecular weight, $M_{w}$, of extruded HDPE at high shear rates. Secondly, a well-developed secondary Newtonian plateau was found for four different polypropylenes between approximately $1 \cdot 10^{6}-8 \cdot 10^{6} 1 / \mathrm{s}[16-$ 20]. In this case, no second shear thinning or thickening region was detected within whole applied high shear rate range. On the other hand, it was found that the secondary Newtonian plateau for specific PP grade can be followed by the shear thickening behaviour occurring at the highest shear rates if the effect of pressure prevails over the effect of viscous dissipation [17].

Finaly, Takahashi et al. [16] compared flow curves, containing secondary Newtonian plateau, for HDPE and UHMWPE samples (having about an order of magnitude different $M_{w}$ ) and concluded that the viscosity dependence on $M_{w}$ is small at high shear rates. Kelly et 
al. [17] provided similar comparison for two PPs with different $M_{w}$ (192000 and 283000$)$ with the suggestion that ' ...molecular size or structure may influence the observed high strain plateau'.

With the aim to understand flow behaviour of melt blown polymers in more detail, three linear isotactic PP samples with melt flow rate between 450-1200 g/10min were characterized over a very wide deformation rate range $\left(10-10^{7} 1 / \mathrm{s}\right)$ by using rotational and capillary rheometry as well as by the instrumented injection molding machine equipped with interchangeable dies. In the second part of this work, the fitting capability of different simple shear viscosity models were evaluated for all tested polymer samples.

\section{EXPERIMENTAL}

In this work, linear isotactic PP Borflow HL504FB (76k), HL508FB (64k) and HL512FB (56k) produced by Borealis Polyolefine have been used. Basic characteristics of their pellets are summarized in Table 1.

Low shear rate viscosity data were measured on an Advanced Rheometric Expansion System (ARES 2000 model, Rheometrics Scientific, USA) at 190, 210 and $230{ }^{\circ} \mathrm{C}$ in parallel plate mode. The aluminium bottom plate with the overflow channel was used to prevent polymer melt leakage flow out of the geometry. A Rosand RH7-2 twin bore capillary rheometer, together with Bagley and Rabinowitsch corrections, has been utilized for the determination of shear viscosities at medium shear rates by using a novel patented orifice die [21-22]. The main advantage of the utilized orifice die is the open downstream region design which eliminates any possibility for artificial pressure increase due to polymer melt touching the downstream wall. In this work, three long dies (length to diameter ratio, $L / D$, equal to 16 , $\left.\mathrm{D}_{1}=0.15 \mathrm{~mm}, \mathrm{D}_{2}=0.5 \mathrm{~mm}, \mathrm{D}_{3}=1 \mathrm{~mm}\right)$ and three orifice dies with the same diameters were used. Close fitting piston tips of the instrument were made from polyether ether ketone 
(PEEK). The PEEK piston tips are used in order to prevent any possible polymer melt leakage flow between the piston tips and the barrel due to very low shear viscosity of the melt blown samples. Furthermore, it was found necessary to use polytetrafluoroethylene tape to prevent polymer melt leakage flow between the die holder and capillary rheometer barrel as it is shown in Figure 2.

The measurements were performed in a constant piston speed mode at the shear rate range of (30-640000) s ${ }^{-1}$ and $230{ }^{\circ} \mathrm{C}$. In our measurements we used pressure transducers (Dynisco, USA) in ranges of (10000) PSI (68.9476 MPa), (1500) PSI (10.3421 MPa), (500) PSI (3.4473 $\mathrm{MPa}$. To improve accuracy of measured data at low shear rates range the highly sensitive pressure transducer (250) PSI (1.7237 MPa) calibrated to its resolution limit was used for recording pressure at the entrance to the orifice capillary die. The compressed air based device, CCS 20 from AMV Messgeräte $\mathrm{GmbH}$, was used to calibrate this pressure transducers by using 69 calibration points.

For high strain rate rheometry at 190, 210 and $230^{\circ} \mathrm{C}$, a high accuracy Fanuc Roboshot S2000i electric high-speed injection molding machine was used, with screw diameter $22 \mathrm{~mm}$ and a maximum barrel pressure rating of $240 \mathrm{MPa}$. The machine was operated in air-shot mode using an instrumented rheometric capillary die nozzle (see Figure 3). Melt pressure was measured at the capillary die entrance at a frequency of $100 \mathrm{~Hz}$ using a Kistler 4021A pressure transducer. Injection screw position and velocity were also monitored at the same frequency. Polymer was injected over a velocity range of $2.6 \mathrm{~mm} / \mathrm{s}$ to $220 \mathrm{~mm} / \mathrm{s}$ firstly through a capillary die of $8 \mathrm{~mm}$ length and diameter $0.5 \mathrm{~mm}$, and then tests were repeated with an orifice die of the same diameter enabling Bagley and Rabinowitsch corrections. Polymer was plasticized in the screw of the molding machine at a screw rotation speed of 2.83 revolutions per second with the back pressure of $0.1 \mathrm{MPa}$. Injection was initiated following a dwell time of 30 s. Process data were collected using a LabView SC2345 data 
acquisition unit triggered by a $24 \mathrm{~V}$ signal from the injection molding machine at the start of injection. More details about this instrument and its accuracy are provided in [17].

\section{SHEAR VISCOSITY MODELS}

In this work, the following simple shear viscosity models with capability to describe the primary and the secondary Newtonian plateau via $\eta_{0}$ and $\eta_{\infty}$ parameter, respectively, were utilized.

\section{4-parametric Cross model [23]}

$\eta(\dot{\gamma})=\eta_{\infty}+\frac{\eta_{0}-\eta_{\infty}}{1+(\lambda \dot{\gamma})^{a}}$

where $\eta_{0}, \eta_{\infty}, \lambda$ and $a$ are model parameters.

\section{4-parametric Carreau model [24]}

$\eta(\dot{\gamma})=\eta_{\infty}+\frac{\eta_{0}-\eta_{\infty}}{\left[1+(\lambda \dot{\gamma})^{2}\right]^{n}}$

where $\eta_{0}, \eta_{\infty}, \lambda$ and $n$ are model parameters.

4-parametric Generalized Quemada model $[25,26]$

$\eta(\dot{\gamma})=\frac{\eta_{\infty}}{\left\{1-\left[1-\left(\frac{\eta_{\infty}}{\eta_{0}}\right)^{\frac{1}{a}}\right] \frac{1}{1+\left(t_{c} \dot{\gamma}\right)^{\frac{1}{a}}}\right\}^{a}}$

where $\eta_{0}, \eta_{\infty}, a$ and $t_{c}$ are model parameters. 
$\eta(\dot{\gamma})=\eta_{\infty}+\frac{\eta_{0}-\eta_{\infty}}{\left[1+(\lambda \dot{\gamma})^{a}\right]^{\left(\frac{1-n}{a}\right)}}$

where $\eta_{0}, \eta_{\infty}, \lambda, a$ and $n$ are model parameters.

$\underline{\text { Suggested 5-parametric Modified Quemada }}$

$\eta(\dot{\gamma})=\frac{\eta_{\infty}}{\left\{1-\left[1-\left(\frac{\eta_{\infty}}{\eta_{0}}\right)^{\frac{1}{n-1}}\right] \frac{1}{1+\left(t_{c} \dot{\gamma}\right)^{\frac{1}{a}}}\right\}^{n-1}}$

where $\eta_{0}, \eta_{\infty}, a, n$ and $t_{c}$ are model parameters.

$\underline{\text { Suggested 5-parametric Modified Carreau model }}$

$\eta=\eta_{\infty}^{1-f}[\eta(\dot{\gamma})]^{f}$

$f=\left[\frac{\tanh [\eta(\dot{\gamma})]}{\tanh \left(\eta_{0}\right)}\right]^{a\left(1^{n^{n_{\infty}}-1}\right)}$

where $\eta(\dot{\gamma})$ is given by Eq.2, and $\eta_{0}, \eta_{\infty}, \lambda, a$ and $n$ are model parameters.

It is important to note that $\dot{\gamma}$ in all above equations represents the shear rate and Eqs. 6-7 can be used to modify any viscosity function defined via $\eta(\dot{\gamma})$.

\section{RESULTS AND DISCUSSION}

In order to keep the relationship between the measured rheological data and molecular structure clear, MWDs and basic molecular weight averages were measured by high temperature gel permeation chromatography for PP extrudates processed (i.e. rheologically evaluated) at high shear rates (see Figure 4 and Table 2). Processed samples exposed to a 
residence time at the processing temperature for about 1 hour were also used for low as well as medium shear rate measurements.

Measured shear viscosity data plotted as a function of shear rate at $230^{\circ} \mathrm{C}$ are provided in Figure 5 for all melt blown polymer samples. The ARES 2000 torque transducer 2K FRTN1 with a $2 \mu \mathrm{Nm}$ low resolution limit allowed measurements of no scattered data only above about 10 1/s. Pressure measurements at very high shear rates, performed on the injection molding machine, were repeated at each given velocity three times, averaged, and then the pressure transducer was calibrated by the help of an additional measurement at the reference injection velocity. This procedure was repeated for all utilized injection velocities and both dies. Gross errors in pressure measurements caused by unwanted recalibration of pressure transducers were excluded from the analysis. Low strain rate primary as well as high strain rate secondary Newtonian plateaus can clearly be identified (summarization is provided in Table 3). Standard deviations for each viscosity point at the secondary Newtonian plateau were found to be typically $0.004,0.006$ and 0.007 Pa.s for $76 \mathrm{k}$, 64k and 56k samples, respectively, which indicates very good reproducibility of performed viscosity measurements. Interestingly, the secondary Newtonian plateau starts at a shear rate of approximately $2 \cdot 10^{6}$ $1 / \mathrm{s}$ and it is well developed up to $7 \cdot 10^{6} 1 / \mathrm{s}$ with no additional second shear thinning region. The fact that there is no additional second shear thinning region indicates no chain scission occurs with the given melt blown PPs at these rates. This finding is similar to the experimental work of Takahashi et al. [16] who report that '.. very little change in molecular weight was observed for HDPE with a weak molecular interaction, even under high shear rates of the second Newtonian region'. 'In the high shear rate above $7 \cdot 10^{6} \mathrm{~s}^{-1}$, where the second non-Newtonian region appears ..., the molecular weight of HDPE seems to gradually decrease'. On the other hand, the occurrence of very well developed secondary Newtonian plateau for PP at $230^{\circ} \mathrm{C}$ between $2 \cdot 10^{6} 1 / \mathrm{s}$ and $7 \cdot 10^{6} 1 / \mathrm{s}$ is in good correspondence with the 
comparable experimental work for conventional low melt flow index polypropylenes $[16,18$, 19] obtained at the same temperature, i.e. at the $230{ }^{\circ} \mathrm{C}$. In more detail, Takahashi et al. [16], utilizing a hydraulically powered capillary rheometer for polypropylene having MFI $=5.8$ g/10min (PP K1016 from Chisso), reported well developed secondary Newtonian plateaus at shear rates of about $1.8 \cdot 10^{6}$ and $6 \cdot 10^{6} 1 / \mathrm{s}$. Similar secondary Newtonian plateaus were reported for a polypropylene with a MFI of $12 \mathrm{~g} / 10 \mathrm{~min}$ (PP 3120MN1 from Appryl) by Haddout and Villoutreix [18] and Benhadou et al. [19], between $1.3 \cdot 10^{6} 1 / \mathrm{s}$ and $8 \cdot 10^{6} 1 / \mathrm{s}$ utilizing an instrumented injection molding machine equipped with a cylindrical instrumented nozzle with variable diameter. This suggests the onset of a secondary Newtonian region is insensitive (or weakly sensitive) to the melt flow index (i.e. on the molecular weight) of polypropylenes at a given temperature. On the other hand, the viscosity at the secondary Newtonian plateau, $\eta_{\infty}$, reported in this work for low molecular weight PPs is almost one order of magnitude lower in comparison with conventional high molecular weight PPs reported in $[16,18,19]$ at the same temperature $230^{\circ} \mathrm{C}$. This can be understood by considering a lower friction between highly oriented macromolecules. At very high shear rates, where entanglements between the chains do not longer exist, intermolecular resistance is much reduced for lower molecular weight PPs in comparison with high molecular weight PPs.

Reynolds number, defined below, was used to determine the character of the flow at the highest shear rate range where a secondary Newtonian plateau occurs. The results of the three tested PP samples are summarized in Table 4.

$$
\operatorname{Re}=\frac{\rho v D}{\eta_{\infty}}
$$

where $\rho$ is the melt density, $v$ is average velocity, $D$ is the capillary diameter and $\eta_{\infty}$ is the melt viscosity at the secondary Newtonian plateau. Data in Table 4 shows Reynolds number 
for the shear rates between $2 \cdot 10^{6}$ and $6.2 \cdot 10^{6} 1 / \mathrm{s}$ varies between 195 and 835 . We can deduce that the flow is laminar.

\section{Flow activation energy:}

Measured values of $\eta_{0}$ and $\eta_{\infty}$ at three applied temperatures (190, 210 and $230^{\circ} \mathrm{C}$ ) allows determination of flow activation energy at low $\left(E_{0}\right)$ as well as at high $\left(E_{\infty}\right)$ shear rates via Arrhenius plot depicted in Figure 6. $E_{0}$ was found to be $56.558 \mathrm{~kJ} / \mathrm{mol}$ for $76 \mathrm{k}, 56.520 \mathrm{~kJ} / \mathrm{mol}$ for $64 \mathrm{k}$ and $56.691 \mathrm{~kJ} / \mathrm{mol}$ for $56 \mathrm{k}$. These are practically identical for all tested polypropylene melts (average value is $56.590 \pm 0.090 \mathrm{~kJ} / \mathrm{mol}$ ). These values of $E_{0}$ are in very good agreement with values reported for low molecular weight melt blown isotactic polypropylenes such as ExxonMobil Escorene PP3546G $\left(\mathrm{E}_{0}=62 \mathrm{~kJ} / \mathrm{mol}, \mathrm{MFI}=1200 \mathrm{~g} / 10\right.$ $\min$ at $\left.230^{\circ} \mathrm{C} / 2.16 \mathrm{~kg}\right)$ or $\mathrm{PP} 3505 \mathrm{G}\left(\mathrm{E}_{0}=46.8 \mathrm{~kJ} / \mathrm{mol}, \mathrm{MFI}=400 \mathrm{~g} / 10 \mathrm{~min}\right.$ at $\left.230^{\circ} \mathrm{C} / 2.16 \mathrm{~kg}\right)$ [13]. On the other hand, $E_{\infty}$ was found to be much smaller, $23.395 \mathrm{~kJ} / \mathrm{mol}$ for $76 \mathrm{k}, 26.916$ $\mathrm{kJ} / \mathrm{mol}$ for $64 \mathrm{k}$ and $25.301 \mathrm{~kJ} / \mathrm{mol}$ for $56 \mathrm{k}$ (average value is $25.204 \pm 1.763 \mathrm{~kJ} / \mathrm{mol}$ ). Relating average values of $E_{\infty}$ and $E_{0}$ yields the following relationship:

$$
E_{\infty}=0.4454 E_{0}
$$

In order to discuss the physical meaning of the significant change between $E_{0}$ and $E_{\infty}$ in more detail let us compare $E_{\infty}$ with flow activation energy of the PP like oligomer called squalane $\left(\mathrm{C}_{30} \mathrm{H}_{62} ; 2,6,10,15,19,23\right.$-hexamethyltetracosane, see Figure 7) having molecular weight equal to $442.8 \mathrm{~g} / \mathrm{mol}$. Viscosity data for squalane have recently been measured over a wide range of temperatures (up to $200^{\circ} \mathrm{C}$ ) and pressures (up to 200MPa) [28]. These data (taken from Table 7 in [28]) together with Arrhenius equation were utilized here to determine average flow activation energy of squalene, $E_{\text {squalane }}=19.804 \pm 1.633 \mathrm{~kJ} / \mathrm{mol}$ (see Figure 8 ). Comparable values of $E_{\text {squalane }}$ and $E_{\infty}$ for isotactic PP strongly supports the conclusion that 
polymer chains of our tested PPs become disentangled at the secondary Newtonian plateau region. The significant change in the flow activation energy of the PPs can thus be attributed to change from entangled to disentangled state of PP chains due to strong shear flow, at which polymer chains become less close packed. This leads to a decrease in monomeric friction coefficient and increased free volume due to coalescence of shaped/aligned i.e. anisometric, free volume cavities. Such void shape spatial change increases the availability of sufficiently large free volume cavities making the flow easier. More detailed discussion on free volume concept of polymer viscosity is provided in [29]. As recognized by Fox and Flory [30], increase in the free volume diminishes flow activation energy for disentangled polymer melts by decreasing number average molecular weight below a critical molecular weight, which is $\sim 13800 \mathrm{~g} / \mathrm{mol}$ for isotactic PP considering molecular weight between chain entanglement points $\mathrm{Me}=6900 \mathrm{~g} / \mathrm{mol}[31]$ (see also [32]).

\section{Effect of viscous dissipation and pressure:}

At very high shear rates, there is simultaneous effect of viscous dissipation and compressibility, both having significant effect on the polymer melt viscosity $[17,20]$.

Viscous dissipation is an irreversible transformation of mechanical energy (the work done by the melt during the shear flow) into heat energy due to internal friction of adjacent polymer chains. Considering the Arrhenius relationship between viscosity and temperature $[33,34]$ as well as the temperature rise due to viscous dissipation, the shear viscosity at the secondary Newtonian region $\eta_{\infty}$, can be expressed as;

$$
\eta_{\infty}(T)=\eta_{\infty}\left(T_{r}\right) e^{\frac{E_{\infty}}{R}\left(\frac{1}{T}-\frac{1}{T_{r}}\right)}
$$

where, $T$ is the actual experimental temperature including effect of viscous dissipation, $T_{r}$ is the reference temperature, $R$ is the universal gas constant $(8.314 \mathrm{~J} / \mathrm{K} / \mathrm{mol})$ and $E_{\infty}$ is the flow activation energy at high shear rates. 
Another factor influencing shear viscosity in the secondary Newtonian plateau region is pressure. The Barus equation [35] handles the relationship between shear viscosity and pressure and leads to the following expression for $\eta_{\infty}$ :

$$
\eta_{\infty}(p)=\eta_{\infty}\left(p_{r}\right) e^{\beta p}
$$

where $p$ is the experimentally measured average pressure ( $\Delta \mathrm{p} / 2$ in this work), $p_{r}$ is the reference (ambient) pressure and $\beta$ is the pressure sensitivity coefficient.

The role of viscous dissipation and pressure for the experimental data reported in this work (i.e. where $\mathrm{T}_{\mathrm{r}}=503.15 \mathrm{~K}$ and $\Delta p$ is the long capillary pressure drop) can be evaluated by combining Eqs. 10-11 leading to Eq. (12).

$$
\eta_{\infty}(T, p)=\eta_{\infty}\left(T_{r}, p_{r}\right) e^{\frac{E_{\infty}}{R}\left(\frac{1}{T}-\frac{1}{T_{r}}\right)+\frac{\beta \Delta p}{2}}
$$

The existence of a well-developed secondary Newtonian region for all three tested melts suggests that the effect of viscous dissipation and pressure are mutually cancelled. In order to test this hypothesis high shear rate experiments in the secondary Newtonian region were followed via FEM simulations performed by solving mass, momentum and energy conservation equations. A commercial software, Compuplast VEL 6.8, was used with Eq.12 as the constitutive equation and applying realistic boundary conditions (wall temperature was imposed to $230^{\circ} \mathrm{C}$ instead of adiabatic, i.e. insulated wall). The pressure sensitivity coefficient $\beta$ was determined through matching calculated and measured pressure drop in given capillary flow for all three materials. In particular, $\beta$ was adjusted to make the increase in apparent shear viscosity due to pressure equal the decrease in viscosity due to shear heating. Simulated flow domain together with utilized structured triangular mesh is provided in Figure 9. The flow was modeled as an axi-symmetric with the grid consisting of 8300 triangle elements, which was sufficient to accurately describe the flow field. In the flow simulation, the following basic polypropylene melt characteristics at $230^{\circ} \mathrm{C}$ were used $\rho=712.33 \mathrm{~kg} / \mathrm{m}^{3}$ [36], 
$\mathrm{Cp}=2705.16 \mathrm{~J} / \mathrm{kg} / \mathrm{K}$ [37], $\kappa=0.2092 \mathrm{~W} / \mathrm{m} / \mathrm{K}$ [38]. The average pressure sensitivity parameter $\beta$ was calculated to be $20.00 \pm 2.9 \mathrm{GPa}^{-1}$ for the given material parameters and processing conditions. This value is in excellent agreement with the pressure sensitivity coefficient $21.03 \pm 4.1 \mathrm{GPa}^{-1}$ reported in [39] for polypropylene melt supporting the considered hypothesis.

It should be noted that $\beta$ taken from the literature [39] was determined by superposition (i.e. shear rate and pressure influencing viscosity were taken into account by a single shift factor), which is shear-rate independent, thus providing a shear rate-independent value of $\beta$. It has been shown in $[40,41,42]$, that the pressure sensitivity parameter in the power-law regime, $\beta^{*}$, can be lower than $\beta$ according to following equation

$\beta^{*}=\mathrm{n} \cdot \beta$

where $n$ is the power-law exponent. Thus, utilization of the shear rate-independent $\beta$ for flow modelling of the secondary Newtonian plateau regime, where $n=1$, can be considered reasonable.

Finally, it has been found that thermal conductivity can increase with shear rate for pseudoplastic polymer solutions. This is attributed to the altered structural state of the liquid (the chains are more aligned) and molecular entanglements (formation of rotating units of entangled clusters) [43]. However, more recently, it has been shown via positron annihilation lifetime spectroscopy measurements that the thermal conductivity decreases with increased free volume, which enhances phonon scattering (hence decreasing the thermal conductivity) [44]. Thus, we consider the utilization of a constant thermal conductivity for the flow modeling in the secondary Newtonian plateau (at which the free volume is increased considerably due to chain disentanglement) as reasonable assuming that the effect of shear rate and free volume on thermal conductivity is mutually cancelled in this flow regime. 


\section{Effect of weight average molecular weight on $\eta_{0}$ and $\eta_{\infty}$ :}

Zero shear viscosity, $\eta_{0}$, and the secondary Newtonian viscosity, $\eta_{\infty}$, are plotted as a function of average molecular weight in log-log-scale in Figure 10. The following power-law equations can be used to fit the experimental data.

$$
\begin{aligned}
& \eta_{0}=4.73 \cdot 10^{-17} M_{w}^{3.622} \\
& \eta_{\infty}=1.19 \cdot 10^{-6} M_{w}{ }^{1.084}
\end{aligned}
$$

If the molecular weight of polymers exceeds the critical molecular weight $M_{c}$, which is about 2-3 times molecular weight between chain entanglement points (i.e. $M_{e} \approx 6900 \mathrm{~g} / \mathrm{mol}$ for isotactic PP [31]), the exponent is about 3.4-3.6, whereas bellow Mc it is about $1[45,46]$. Wasserman and Graessley [45, 47, 48] reported the following relationship for linear isotactic polypropylene:

$$
\eta_{0}(\text { Pa.s })=5.32 \cdot 10^{-17} M_{w}^{3.60}\left(190{ }^{\circ} \mathrm{C}\right)
$$

As it can be seen, parameters of Equation (16) agree well with the experimentally determined relationship given by Eq.14, confirming the existence of entanglements between the chains at very low shear rates. It also supports the validity of the zero shear viscosities and average molecular weights reported in this work for the low molecular weight polypropylenes. In the case of the secondary Newtonian viscosity, $\eta_{\infty}$, the proportionality constant is about 10 orders of magnitudes higher than in the case of zero shear rate viscosity and the exponent on $M_{w}$ is close to 1 . According to Rouse-Bueche molecular theory [45, 49], the viscosity of molten polymers with no entangled molecules is proportional to molecular weight. This suggests there are no entanglements between the chains at the secondary Newtonian region and the resistance against the flow is given here only by the friction between the highly oriented macromolecular chains (depending predominantly on their size, packing level and conformational state). 
If Eqs.14-15 are combined the secondary Newtonian viscosity, $\eta_{\infty}$, can be expressed via the zero shear viscosity, $\eta_{0}$, and weight average molecular weight, $M_{w}$, as follows:

$$
\eta_{\infty}=0.2516 \cdot 10^{11} \eta_{0} \mathrm{M}_{\mathrm{w}}^{-2.538}
$$

Additionally, it has been proved experimentally by Takahashi et.al. [16], there is no wall slip at very high shear rates for $\mathrm{PP}$ at $230^{\circ} \mathrm{C}$ (i.e. for the same polymer and flow conditions utilized in our work). In their experiments, the authors have used two kinds of the capillaries with same L/D ratio (20) but different diameters $(0.5 \mathrm{~mm}, 1 \mathrm{~mm})$. Their findings support the validity of high strain rate rheological measurements performed in this work as well as the conclusion that the polymers chains are fully disentangled at high shear rates.

\section{Rheological modeling:}

In this section we investigate the fitting capabilities of conventional (Eqs. 1-4) as well as modified (Eqs. 5-7) rheological models, suggested here for the first time, to describe measured rheological data. Model parameters characterizing the primary and the secondary Newtonian plateau (i.e. $\eta_{0}$, and $\eta_{\infty}$ ) were fixed whereas the remaining parameters were varied to minimize least squares between the experimental data and model predictions. Comparison between the measured data and model fitting curves is provided in Figs. 11-13. Fitting errors for each model and given polymer melt were evaluated via the Root Mean Squared Error (RMSE) defined as

$$
R M S E=\sqrt{\frac{1}{\delta} \sum_{i=1}^{\delta}\left[\log \left(\eta_{i}\right)-\log \left(\hat{\eta}_{i}\right)\right]^{2}}
$$

where $\delta$ is the number of measured points, $\eta_{\mathrm{i}}$ and $\hat{\eta}_{i}$ represent measured and predicted shear viscosity points at given shear rate (see Tables 5-7). All model parameters are summarized in Tables 8-10. 
Based on the Tables 5-7 and Figs. 11-13, the following conclusions can be formulated:

- 5-parametric viscosity models provide a closer fit to describing the measured data than 4-parametric models, as expected.

- The capability of utilized models to describe the measured data decreases in the following order: Modified Quemada model, Modified Carreau model, CarreauYasuda model, Cross model, Generalized Quemada model and Carreau model. Note that the Total RMSE, provided in Table 11 for each model, represents the sum of Root mean squared error determined for all three polypropylene samples (Total RMSE).

- Modified Quemada model and Cross models more accurately describe the measured shear viscosity data from all utilized 5-parametric and 4-parametric models, respectively.

One may consider under what circumstances are proposed modified 5 parameter models more desirable than the conventional models? One of the key reasons for going to 5 parameters models are their improved flexibility do describe experimental data, especially at the high shear rate range. For example, the 4-parametric Cross model over predicts shear viscosity by $12 \%$ (average) - $26 \%$ (maximum deviation) at shear rates between $1.2 \cdot 10^{5} 1 / \mathrm{s}$ and $6.73 \cdot 10^{6}$ $1 / \mathrm{s}$ for given PPs at $\mathrm{T}=230^{\circ} \mathrm{C}$. Consequently, when trying to predict the pressure drop in capillary flows for the given materials and processing conditions utilizing the Cross model, the error in the predicted pressure drop can reach $26 \%$, which is unacceptable considering that the experimental pressure drops can be in order of tens or hundreds MPa at such high shear rates. 


\section{CONCLUSION}

In this work, three linear melt blown isotactic polypropylenes, with weight average molecular weights between $56250-75850 \mathrm{~g} / \mathrm{mol}$, have been characterized at $230{ }^{\circ} \mathrm{C}$ over a very wide shear strain rate range $\left(10-10^{7} 1 / \mathrm{s}\right)$ by using; rotational and twin bore capillary rheometer equipped with a novel inert orifice die design as well as by an instrumented rheometric nozzle on an injection molding machine. Flow activation energy at low $\left(E_{0}\right)$ and high $\left(E_{\infty}\right)$ shear rates was found to be $56.590 \pm 0.090 \mathrm{~kJ} / \mathrm{mol}$ and $25.204 \pm 1.763 \mathrm{~kJ} / \mathrm{mol}$, respectively. A primary Newtonian plateau, pseudoplastic region and well developed secondary Newtonian plateau (occurring between $2 \cdot 10^{6}-7 \cdot 10^{6} \quad 1 / \mathrm{s}$ ) were identified for all polypropylene melts. Based on the estimated pressure sensitivity coefficient, $\beta=20.00 \mathrm{GPa}^{-1}$, which is typical value for polypropylene melts [39], it was deduced that the effect of viscous dissipation and pressure is mutually cancelled, i.e. that the measured viscosity data can be considered as the true material property within whole applied shear rate range. For the first time, it has been revealed that the secondary Newtonian viscosity, $\eta_{\infty}$, depends linearly on the

weight average molecular weight, $M_{w}$, in $\log -\log$ scale as $\eta_{\infty}=1.19 \cdot 10^{-6} M_{w}{ }^{1.084}$. The observed slope close to 1 between $\eta_{\infty}$ and $M_{w}$ suggests that polymer chains in the melt are disentangled at the secondary Newtonian plateau region. This conclusion is supported by the experimental observation that the high shear rate flow activation energy $E_{\infty}$ for given PP melts is comparable with the flow activation energy of PP like oligomer (squalane, $\mathrm{C}_{30} \mathrm{H}_{62}$; 2,6,10,15,19,23-hexamethyltetracosane).

The measured flow curves were fitted by six different viscosity models. Two modified models, namely a modified Carreau and a Quemada model were developed. It has been found the shear flow data could be more accurately described over the wide strain rate range by the newly suggested models. The accuracy of curve fitting decreases in the 
following order: Modified Quemada model, Modified Carreau model, Carreau-Yasuda model, Cross model, Generalized Quemada model and Carreau model.

\section{Acknowledgments}

The authors wish to acknowledge Grant Agency of the Czech Republic (Grant registration No. 16-05886S, Title: Investigation the effect of polymer melt shear and elongational rheology on production stability of meltblown nanofibers and films) for the financial support. The author also wishes to acknowledge Joachim Fiebig (Borealis Polyolefine) for donation of the polypropylene melt blown samples and help with the GPC measurements and analysis. 


\section{REFFERENCES}

1. C.J. Ellison, A. Phatak, D.W. Giles, C.W. Macosko, F.S. Bates, Melt blown nanofibers: Fiber diameter distributions and onset of fiber breakup, Polymer 48 (2007) 3306-3316.

2. R. Nayak, I.L. Kyratzis, Y.B. Truong, R. Padhye, L. Arnold, G. Peeters, M. O’Shea, L. Nichols, Fabrication and characterization of polypropylene nanofibres by meltblowing process using different fluids, J. Mat. Sci. 48 (2013) 273-281.

3. F. Zuo, D.H. Tan, Z. Wang, S. Jeung, C.W. Macosko, F.S. Bates, Nanofibers from melt blown fiber-in-fiber polymer blends, ACS Mac. Letters 2 (2013) 301-305.

4. G.F. Ward, Meltblown nanofibres for nonwoven filtration applications, Filtr. and Separ. 38 (2001) 42-43.

5. J.E. Brang, A. Wilkie, J.S. Haggard, Method and apparatus for production of meltblown nanofibers, US patent US20080023888 A1 (2008).

6. R. Nayak, R. Padhye, I.L. Kyratzis, Y.B. Truong, L. Arnold, Recent advances in nanofibre fabrication techniques, Tex. Res. J. 82 (2012) 129-147.

7. R.A. Chapman, Applications of nonwovens in technical textiles, Elsevier, 2010.

8. A. Wilkie, J. Haggard, Nanofiber melt blown nonwovens-A new low, Inter. Fib. J. 22 (2007) 48-49.

9. J. Drabek, M. Zatloukal, Rheological evaluation of melt blown polymer melt, AIP Con. Pro. 1526 (2013) 237-247.

10. A. Eckstein, C. Friedrich, A. Lobbrecht, R. Spitz, Comparison of the viscoelastic properties of syndio - and isotactic polypropylenes, Acta Polymerica 48 (1997) 41-46.

11. M. Gahleitner, Melt rheology of polyolefins, Prog. in Pol. Sci. (Oxford) 26 (2001) 895944. 
12. J.H. Lin, Y.J. Pan, C.F. Liu, C.L. Huang, C.T. Hsieh, C.K. Chen, Z.I. Lin, C.W. Lou, Preparation and compatibility evaluation of polypropylene/high density polyethylene polyblends, Materials 8 (2015) 8850-8859.

13. Y. Wang, Application of Polymer Rheology in Melt Blowing Process and Online Rheological Sensor, University of Tennessee-Knoxville, Ph.D. Thesis (2004).

14. R. Nayak, Fabrication and characterization of polypropylene nanofibres by melt electrospinning and meltblowing. RMIT University, Ph.D. Thesis (2012)

15. D.H. Tan, C. Zhou, C.J. Ellison, S. Kumar, C.W. Macosko, F.S. Bates, Meltblown fibers: Influence of viscosity and elasticity on diameter distribution, J. Non-New. Flu. Mech. 165 (2010) 892-900.

16. H. Takahashi, T. Matsuoka, T. Kurauchi, Rheology of polymer melts in high shear rate, J. App. Pol. Sci. 30 (1985) 4669-4684.

17. A.L. Kelly, A.T. Gough, B.R. Whiteside, P.D. Coates, High shear strain rate rheometry of polymer melts, J. App. Pol. Sci. 114 (2009) 864-873.

18. A. Haddout, G. Villoutreix, Polymer melt rheology at high shear rates, Int. Pol. Proc. 15 (2000) 291-296.

19. M. Benhadou, A. Haddout, G. Villoutreix, Injection of polypropylene reinforced with short glass fibers: Rheological behavior, J. Reinf. Plast. Comp. 26 (2007) 1357-1366.

20. M. Rides, A.L. Kelly, C.R.G. Allen, An investigation of high rate capillary extrusion rheometry of thermoplastics, Pol. Testing 30 (2011) 916-924.

21. M. Zatloukal, J. Musil, Analysis of entrance pressure drop techniques for extensional viscosity determination, Pol. Testing 28 (2009) 843-853.

22. M. Zatloukal, Measurements and modeling of temperature-strain rate dependent uniaxial and planar extensional viscosities for branched LDPE polymer melt, Polymer 104 (2016) 258-267. 
23. M.M. Cross, Rheology of non-Newtonian fluids: A new flow equation for pseudoplastic systems, J. Coll. Sci. 20 (1965) 417-437.

24. P.J. Carreau, Rheological equations from molecular network theories, Trans. Soc. Rheol. $16(1972) 99-127$.

25. D. Quemada, P. Flaud, P.H. Jezequel, Rheological properties and flow of concentrated disperse media I - modelling of steady and unsteady behavior, Chem. Eng. Commun. 32 (1985) 61-83.

26. T. Fang, H. Zhang, T.T. Hsieh, C. Tiu, Rheological behavior of cocoa dispersion with cocoa butter replacers, J. Text. Stud. 28 (1997) 11-26.

27. K. Yasuda, R.C. Armstrong, R.E. Cohen, Shear flow properties of concentrated solutions of linear and star branched polystyrenes, Rheo. Acta 20 (1981) 163-178.

28. K.A.G. Schmidt, D. Pagnutti, M.D. Curran, A. Singh, J.P.M. Trusler, G.C. Maitland, M. McBride-Wright, New experimental data and reference models for the viscosity and density of squalane, J. of Chem. And Eng. Data 60 (2015) 137-150.

29. L.A. Utracki, T. Sedlacek, Free volume dependence of polymer viscosity, Rheo. Acta 46 (2007) 479-494.

30. T.G. Fox Jr., P.J. Flory, Second-order temperature and related properties of polystyrene. I. Influence of molecular weight, J. of App. Physics 21 (1950) 581-591.

31. A. Eckstein, J. Suhm, C. Friedrich, R.-D. Maier, J. Sassmannshausen, M. Bochmann, R. Mülhaupt, Determination of plateau moduli and entanglement molecular weights of isotactic, syndiotactic, and atactic polypropylenes synthesized with metallocene catalysts, Macromolecules 31 (1998) 1335-1340.

32. J.D. Ferry, Viscoelastic properties of polymers, $3^{\text {rd }}$ edition, John Wiley \& Sons, 1980.

33. J. M. Dealy, K.F. Wissbrun, Melt Rheology and Its Role in Plastics Processing, Chapman \& Hall, 1995. 
34. R.B. Bird, R.C. Armstrong, O. Hassager, Dynamics of Polymeric Liquids, Volume 1: Fluid Mechanics, 2nd Edition, Wiley, 1987.

35. C. Barus, Isothermals, isopiestics and isometrics relative to viscosity, Am. J. Sci. 45 (1893) 87-96.

36. Y.G. Li, C.B. Park, Materials and Interfaces: Effects of branching on the pressurevolume-temperature behaviors of $\mathrm{PP} / \mathrm{CO}_{2}$ solutions, Ind. Eng. Chem. Res. 48 (2009) 6633-6640.

37. D.W. Van Krevelen, K. te Nijenhuis, Properties of Polymers, Their Correlation with Chemical Structure; their Numerical Estimation and Prediction from Additive Group Contributions, 4th Edition, Elsevier Science, 2009.

38. T.R. Fuller, A.L. Fricker, Thermal conductivity of polymer melts, J. App. Pol. Sci. 15 (1971) 1729-1736.

39. T. Sedlacek, M. Zatloukal, P. Filip, A. Boldizar, P. Saha, On the effect of pressure on the shear and elongational viscosities of polymer melts, Pol. Eng. Sci. 44 (2004) 1328-1337.

40. D.M. Binding, M.A. Couch, K. Walters, The pressure dependence of the shear and elongational properties of polymer melts, J. of Non-New. Fl. Mech. 79 (1998) 137-155.

41. M.A. Couch, D.M. Binding, High pressure capillary rheometry of polymeric fluids, Polymer 41 (2000) 6323-6334.

42. R. Cardinaels, P. Van Puyvelde, P. Moldenaers, Evaluation and comparison of routes to obtain pressure coefficients from high-pressure capillary rheometry data, Rheo. Acta 46 (2007) 495-505.

43. D.R. Lee, Shear rate dependence of thermal conductivity and its effect on heat transfer in a non-Newtonian flow system, Kor. J. of Chem. Eng. 15 (1998) 252-261. 
44. G. Xue, J. Zhong, S. Gao, B. Wang, Correlation between the free volume and thermal conductivity of porous poly(vinyl alcohol)/reduced graphene oxide composites studied by positron spectroscopy, Carbon 96 (2016) 871-878.

45. J.M. Dealy, R.G. Larson, Structure and rheology of molten polymers: from structure to flow behavior and back again, Hanser Publishers, 2006.

46. D. Auhl, F.J. Stadler, H. Münstedt, Comparison of molecular structure and rheological properties of electron-beam- and gamma-irradiated polypropylene, Macromolecules 45 (2012) 2057-2065.

47. S.H. Wasserman, W.W. Graessley, Prediction of linear viscoelastic response for entangled polyolefin melts from molecular weight distribution, Pol. Eng. Sci. 36 (1996) $852-861$.

48. G.R. Zeichner, P.D. Patel, A comprehensive evaluation of polypropylene melt rheology, Proc. 2nd world congress of chem. Eng. 6.9 Montreal, 1981.

49. F. Bueche, Viscosity, self-diffusion, and allied effects in solid polymers, J. Chem. Phys. 20 (1952) 1959-1964. 
TABLE 1. Basic characteristics of utilized melt blown polypropylenes (pellets).

\begin{tabular}{|c|c|c|c|c|c|c|c|}
\hline $\begin{array}{c}\text { Sample } \\
\text { Name }\end{array}$ & 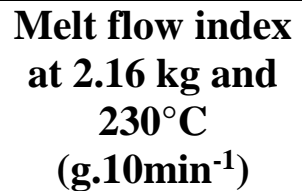 & $\begin{array}{c}\text { DSC peak } \\
\text { melting point } \\
\left({ }^{\circ} \mathrm{C}\right)\end{array}$ & $\underset{\left(\text { g.mol }^{-1}\right)}{\mathbf{M}_{\mathbf{n}}}$ & $\underset{(\text { g.mol }}{\left.\mathbf{M}_{w}{ }^{-1}\right)}$ & $\begin{array}{c}\mathbf{M}_{\mathbf{z}} \\
\left(\mathrm{g} . \mathrm{mol}^{-1}\right)\end{array}$ & $\begin{array}{c}\mathbf{M}_{\mathbf{z}+1} \\
\left(\mathbf{g} . \mathrm{mol}^{-1}\right)\end{array}$ & $\begin{array}{c}\mathbf{M}_{\mathbf{w}} / \mathbf{M}_{\mathbf{n}} \\
(-)\end{array}$ \\
\hline HL504FB & 450 & $161-165$ & 20100 & 112500 & 284500 & 510500 & 5.60 \\
\hline HL508FB & 800 & $156-160$ & 17050 & 104500 & 282000 & 533000 & 6.13 \\
\hline HL512FB & 1200 & $156-160$ & 16950 & 90950 & 220500 & 384500 & 5.37 \\
\hline
\end{tabular}

TABLE 2. Molecular characteristics of utilized melt blown polypropylene melts (processed samples, i.e. high shear rate extrudates).

\begin{tabular}{|c|c|c|c|c|c|}
\hline $\begin{array}{c}\text { Sample } \\
\text { Name }\end{array}$ & $\begin{array}{c}\mathrm{Mn}_{\mathbf{n}} \\
\left(\mathrm{g} \cdot \mathrm{mol}^{-1}\right)\end{array}$ & $\begin{array}{c}M_{w} \\
\left(\text { g. } \cdot \mathbf{m o l}^{-1}\right)\end{array}$ & $\begin{array}{c}\mathbf{M}_{\mathrm{z}} \\
\left(\mathrm{g} \cdot \mathrm{mol}^{-1}\right)\end{array}$ & $\begin{array}{c}\mathbf{M}_{\mathrm{z}+1} \\
\left(\mathrm{~g} \mathrm{~mol}^{-1}\right)\end{array}$ & $\begin{array}{c}\mathbf{M}_{\mathbf{w}} / \mathbf{M}_{\mathbf{n}} \\
(-)\end{array}$ \\
\hline HL504FB (76k) & 17200 & 75850 & 165500 & 278000 & 4.41 \\
\hline HL508FB (64k) & 14650 & 63750 & 138000 & 235500 & 4.35 \\
\hline HL512FB (56k) & 14250 & 56250 & 114500 & 187500 & 3.95 \\
\hline
\end{tabular}

TABLE 3. Summary of experimentally determined values for zero shear viscosity, $\eta_{0}$, and secondary Newtonian viscosity, $\eta_{\infty}$, at $230{ }^{\circ} \mathrm{C}$.

\begin{tabular}{|c|c|c|c|c|}
\hline $\begin{array}{c}\text { Sample } \\
\text { name }\end{array}$ & $\begin{array}{c}\boldsymbol{\eta}_{\mathbf{0}} \\
(\text { Pa.s) }\end{array}$ & $\begin{array}{c}\text { Standard deviation for } \boldsymbol{\eta}_{\mathbf{0}} \\
\text { (Pa.s) }\end{array}$ & $\begin{array}{c}\boldsymbol{\eta}_{\infty} \\
(\text { Pa.s })\end{array}$ & $\begin{array}{c}\text { Standard deviation for } \boldsymbol{\eta}_{\infty} \\
\text { (Pa.s) }\end{array}$ \\
\hline $76 \mathrm{k}$ & 22.80 & 1.149 & 0.229 & 0.0025 \\
\hline $64 \mathrm{k}$ & 11.27 & 0.671 & 0.199 & 0.0018 \\
\hline $56 \mathrm{k}$ & 7.79 & 0.312 & 0.165 & 0.0005 \\
\hline
\end{tabular}

TABLE 4. Calculated Reynolds numbers at the secondary Newtonian region for all three tested polymer melts, $\mathrm{T}=230^{\circ} \mathrm{C}$.

\begin{tabular}{|c|c|c|c|}
\hline $\begin{array}{c}\text { Shear rate } \\
(\mathbf{1} / \mathbf{s})\end{array}$ & $\begin{array}{c}\text { Re, 56k } \\
(-)\end{array}$ & $\begin{array}{c}\text { Re, 64k } \\
(-)\end{array}$ & $\begin{array}{c}\text { Re, } 76 k \\
(-)\end{array}$ \\
\hline 2010342 & 271 & 225 & 195 \\
\hline 3184333 & 429 & 357 & 309 \\
\hline 5049088 & 681 & 566 & 490 \\
\hline 6195200 & 835 & 694 & 601 \\
\hline
\end{tabular}


TABLE 5. Fitting error (Root mean squared error - RMSE) for each utilized model sorted from the best to the worst for linear PP Borflow 76k, $\mathrm{T}=230^{\circ} \mathrm{C}$.

\begin{tabular}{|l|c|}
\hline \multicolumn{1}{|c|}{ Model name } & RMSE \\
\hline Modified Quemada model & 0.018276236 \\
\hline Modified Carreau model & 0.029749727 \\
\hline Carreau-Yasuda model & 0.040775109 \\
\hline Cross model & 0.047118675 \\
\hline Generalized Quemada model & 0.049006845 \\
\hline Carreau model & 0.065738895 \\
\hline
\end{tabular}

TABLE 6. Fitting error (Root mean squared error - RMSE) for each utilized model sorted from the best to the worst for linear PP Borflow $64 \mathrm{k}, \mathrm{T}=230^{\circ} \mathrm{C}$.

\begin{tabular}{|l|c|}
\hline \multicolumn{1}{|c|}{ Model name } & RMSE \\
\hline Modified Quemada model & 0.025431753 \\
\hline Modified Carreau model & 0.027975200 \\
\hline Carreau-Yasuda model & 0.035497268 \\
\hline Cross model & 0.047207561 \\
\hline Generalized Quemada model & 0.048729021 \\
\hline Carreau model & 0.067596955 \\
\hline
\end{tabular}

TABLE 7. Fitting error (Root mean squared error - RMSE) for each utilized model sorted from the best to the worst for linear PP Borflow 56k, $\mathrm{T}=230^{\circ} \mathrm{C}$.

\begin{tabular}{|l|c|}
\hline \multicolumn{1}{|c|}{ Model name } & RMSE \\
\hline Modified Quemada model & 0.022267806 \\
\hline Modified Carreau model & 0.028009255 \\
\hline Carreau-Yasuda model & 0.038134394 \\
\hline Cross model & 0.047852717 \\
\hline Generalized Quemada model & 0.049003044 \\
\hline Carreau model & 0.066374374 \\
\hline
\end{tabular}

TABLE 8. Fitting parameters for each utilized model for $76 \mathrm{k}, \mathrm{T}=230{ }^{\circ} \mathrm{C}$.

\begin{tabular}{|l|c|c|c|c|c|c|}
\hline \multicolumn{1}{|c|}{ Model name } & $\begin{array}{c}\boldsymbol{\eta}_{\mathbf{0}} \\
(\text { Pa.s) }\end{array}$ & $\begin{array}{c}\boldsymbol{\lambda} \\
(\mathbf{s})\end{array}$ & $\begin{array}{c}\boldsymbol{a} \\
(-)\end{array}$ & $\begin{array}{c}\boldsymbol{n} \\
(-)\end{array}$ & $\begin{array}{c}\boldsymbol{\eta}_{\infty} \\
(\mathbf{P a . s})\end{array}$ & $\begin{array}{c}\boldsymbol{t}_{\mathbf{c}} \\
(\mathbf{s})\end{array}$ \\
\hline Cross model & 22.80 & 0.000356 & 0.916622 & - & 0.229 & - \\
\hline Carreau model & 22.80 & 0.000548 & - & 0.434384 & 0.229 & - \\
\hline Carreau-Yasuda model & 22.80 & 0.000222 & 0.714663 & $1 \times 10^{-12}$ & 0.229 & - \\
\hline Generalized Quemada model & 22.80 & - & 1.085421 & - & 0.229 & 0.00000297400 \\
\hline Modified Quemada model & 22.80 & - & 0.192343 & 0.888196 & 0.229 & 0.00148998839 \\
\hline Modified Carreau model & 22.80 & 0.002294 & 6.141027 & 0.238632 & 0.229 & - \\
\hline
\end{tabular}


TABLE 9. Fitting parameters for each utilized model for $64 \mathrm{k}, \mathrm{T}=230{ }^{\circ} \mathrm{C}$.

\begin{tabular}{|l|c|c|c|c|c|c|}
\hline \multicolumn{1}{|c|}{ Model name } & $\begin{array}{c}\boldsymbol{\eta}_{\mathbf{0}} \\
(\text { Pa.s) }\end{array}$ & $\begin{array}{c}\boldsymbol{\lambda} \\
(\mathbf{s})\end{array}$ & $\begin{array}{c}\boldsymbol{a} \\
(-)\end{array}$ & $\begin{array}{c}\boldsymbol{n} \\
(-)\end{array}$ & $\begin{array}{c}\boldsymbol{\eta}_{\infty} \\
(\text { Pa.s) }\end{array}$ & $\begin{array}{c}\boldsymbol{t}_{\mathbf{c}} \\
(\mathbf{s})\end{array}$ \\
\hline Cross model & 11.27 & 0.000203 & 0.889544 & - & 0.199 & - \\
\hline Carreau model & 11.27 & 0.000282 & - & 0.442027 & 0.199 & - \\
\hline Carreau-Yasuda model & 11.27 & 0.000101 & 0.644103 & $1 \times 10^{-12}$ & 0.199 & - \\
\hline Generalized Quemada model & 11.27 & - & 1.141995 & - & 0.199 & 0.00000278757 \\
\hline Modified Quemada model & 11.27 & - & 0.152248 & 0.920448 & 0.199 & 0.00098232952 \\
\hline Modified Carreau model & 11.27 & 0.003327 & 15.29982 & 0.154333 & 0.199 & - \\
\hline
\end{tabular}

TABLE 10. Fitting parameters for each utilized model for $56 \mathrm{k}, \mathrm{T}=230^{\circ} \mathrm{C}$.

\begin{tabular}{|l|c|c|c|c|c|c|}
\hline \multicolumn{1}{|c|}{ Model name } & $\begin{array}{c}\boldsymbol{\eta}_{\mathbf{0}} \\
(\text { Pa.s) }\end{array}$ & $\begin{array}{c}\boldsymbol{\lambda} \\
(\mathbf{s})\end{array}$ & $\begin{array}{c}\boldsymbol{a} \\
\mathbf{( - )}\end{array}$ & $\begin{array}{c}\boldsymbol{n} \\
\mathbf{( - )}\end{array}$ & $\begin{array}{c}\boldsymbol{\eta}_{\infty} \\
(\mathbf{P a . s})\end{array}$ & $\begin{array}{c}\boldsymbol{t}_{\mathbf{c}} \\
(\mathbf{s})\end{array}$ \\
\hline Cross model & 7.79 & 0.000128 & 0.909926 & - & 0.165 & - \\
\hline Carreau model & 7.79 & 0.000191 & - & 0.442092 & 0.165 & - \\
\hline Carreau-Yasuda model & 7.79 & 0.000070 & 0.666422 & $1 \times 10^{-12}$ & 0.165 & - \\
\hline Generalized Quemada model & 7.79 & - & 1.100310 & - & 0.165 & 0.00000228669 \\
\hline Modified Quemada model & 7.79 & - & 0.078774 & 0.959896 & 0.165 & 0.00065601827 \\
\hline Modified Carreau model & 7.79 & 0.006015 & 60.95602 & 0.092772 & 0.165 & - \\
\hline
\end{tabular}

TABLE 11. Sum of fitting errors (Root mean squared error - RMSE) for each utilized model sorted from the best to the worst for all three linear PP Borflow samples, $\mathrm{T}=230^{\circ} \mathrm{C}$.

\begin{tabular}{|l|c|}
\hline \multicolumn{1}{|c|}{ Model name } & Total RMSE \\
\hline Modified Quemada model & 0.065975795 \\
\hline Modified Carreau model & 0.085734182 \\
\hline Carreau-Yasuda model & 0.114406771 \\
\hline Cross model & 0.142178953 \\
\hline Generalized Quemada model & 0.146738910 \\
\hline Carreau model & 0.199710224 \\
\hline
\end{tabular}




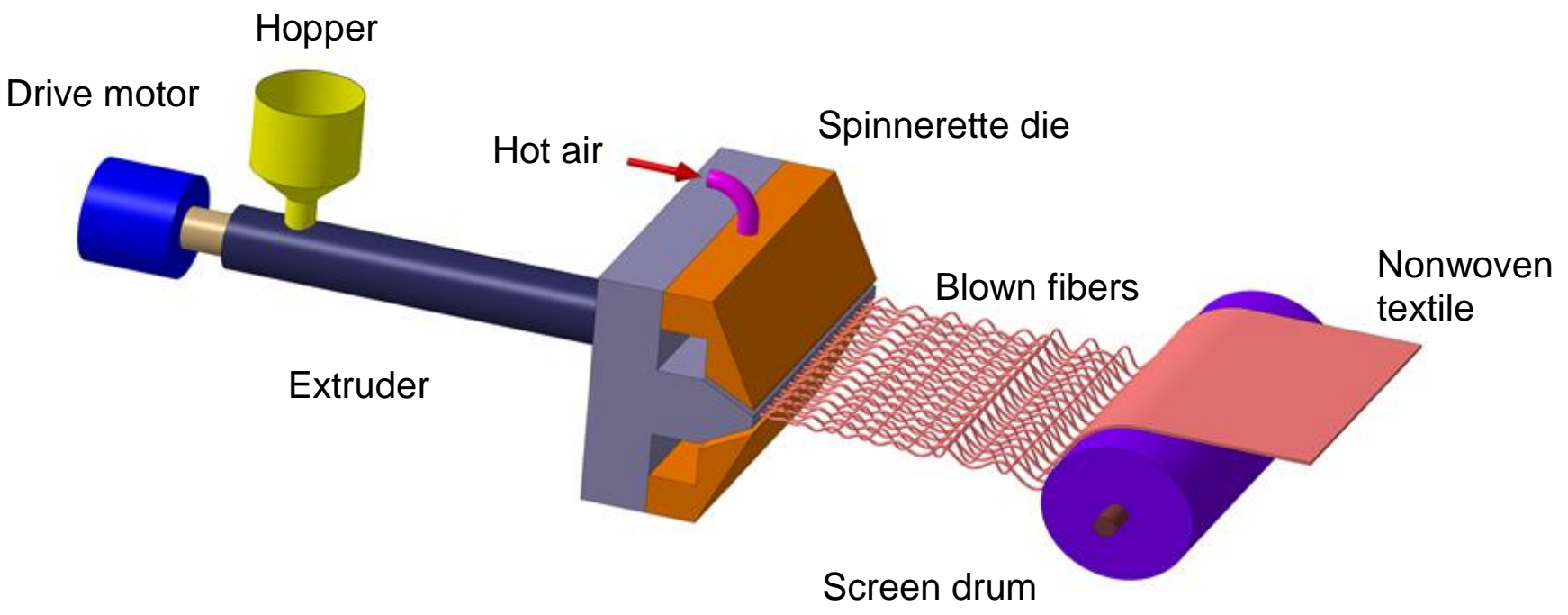

Figure 1. Schematic of the melt blown process. 
2a)

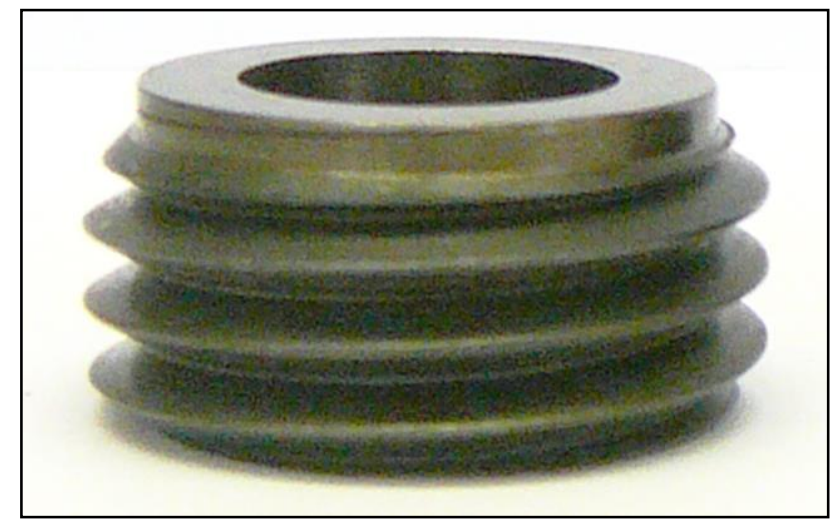

2c)

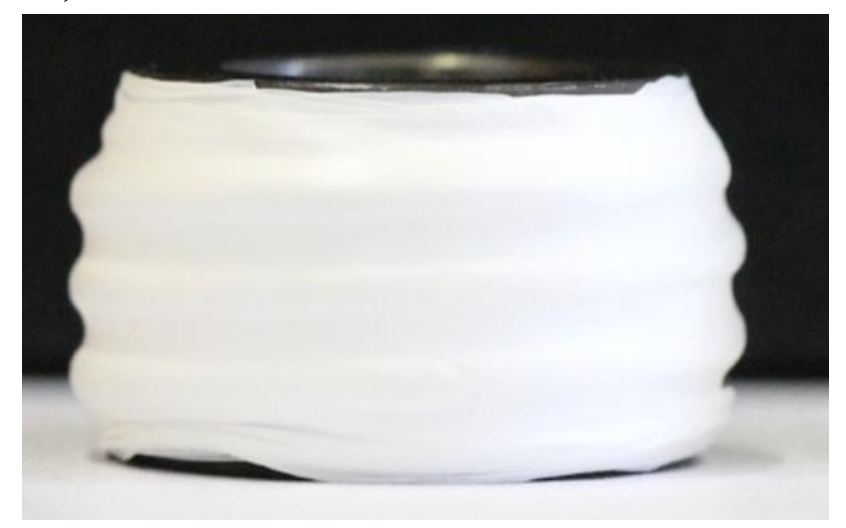

2b)

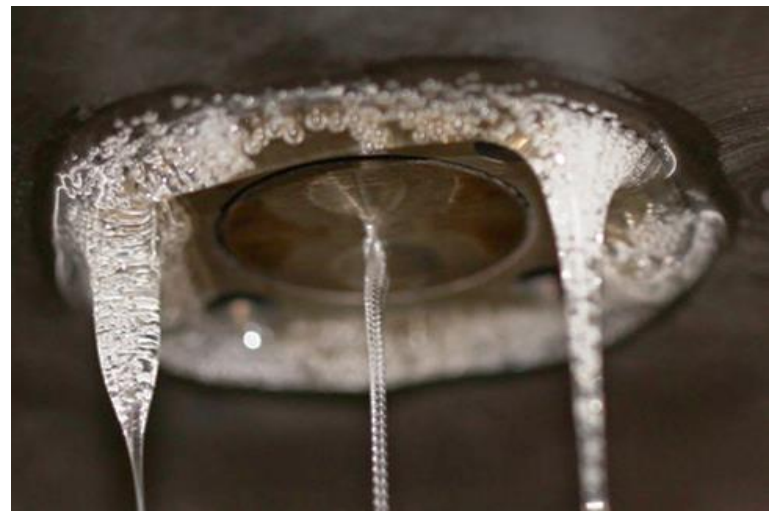

2d)

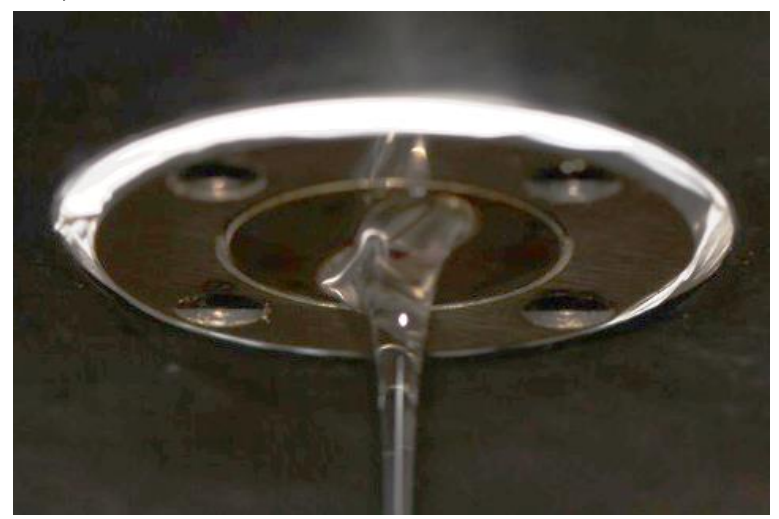

Figure 2. Visualization of die holder and bottom view of the die holder with the capillary die connected to barrel of the capillary during rheological measurements without $(2 \mathrm{a}-2 \mathrm{~b})$ and with the polytetrafluoroethylene tape (2c-2d). 


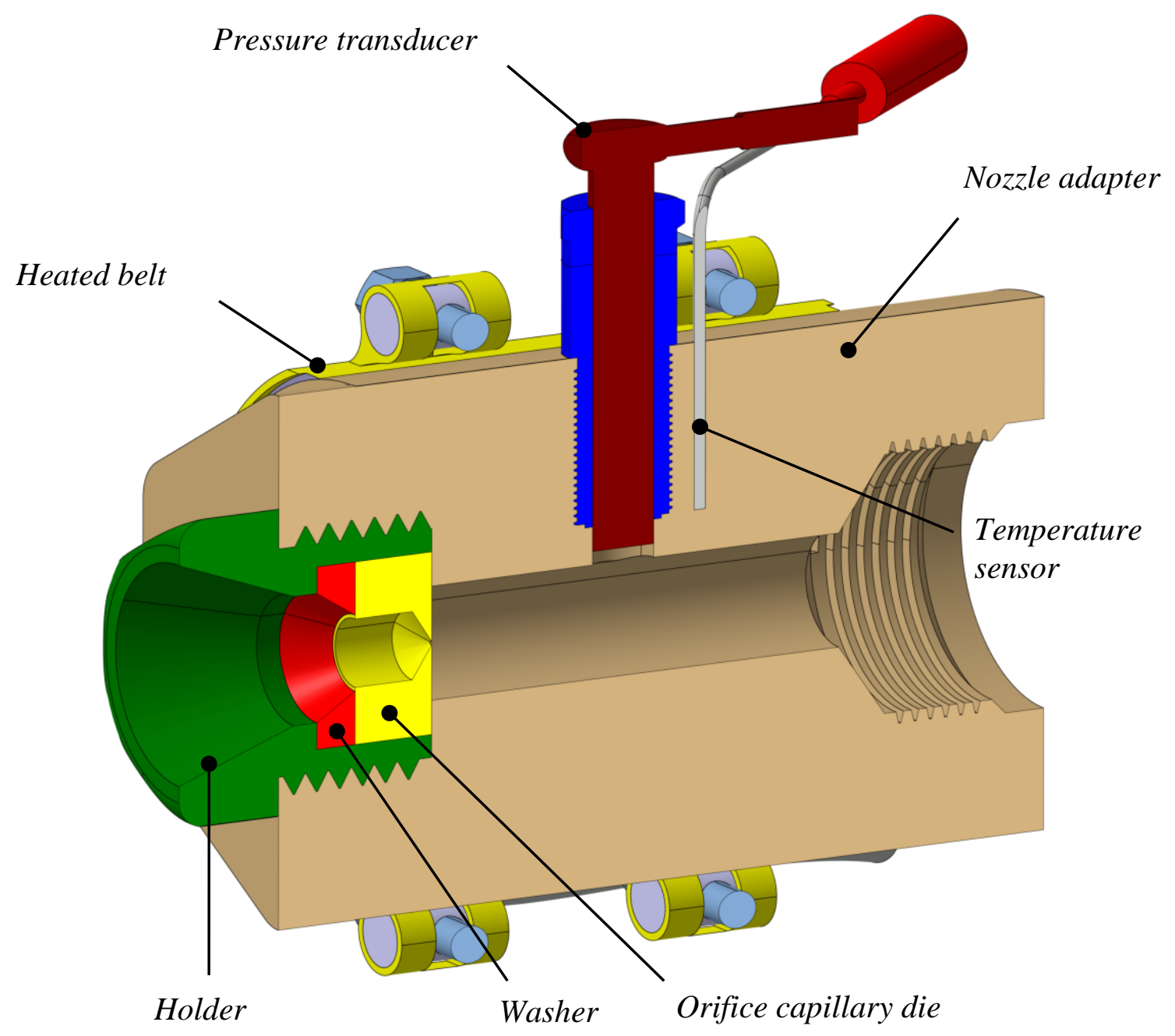

Figure 3. Schematic cross-section of assembled parts for the instrumented capillary nozzle fitted to the injection molding machine. 


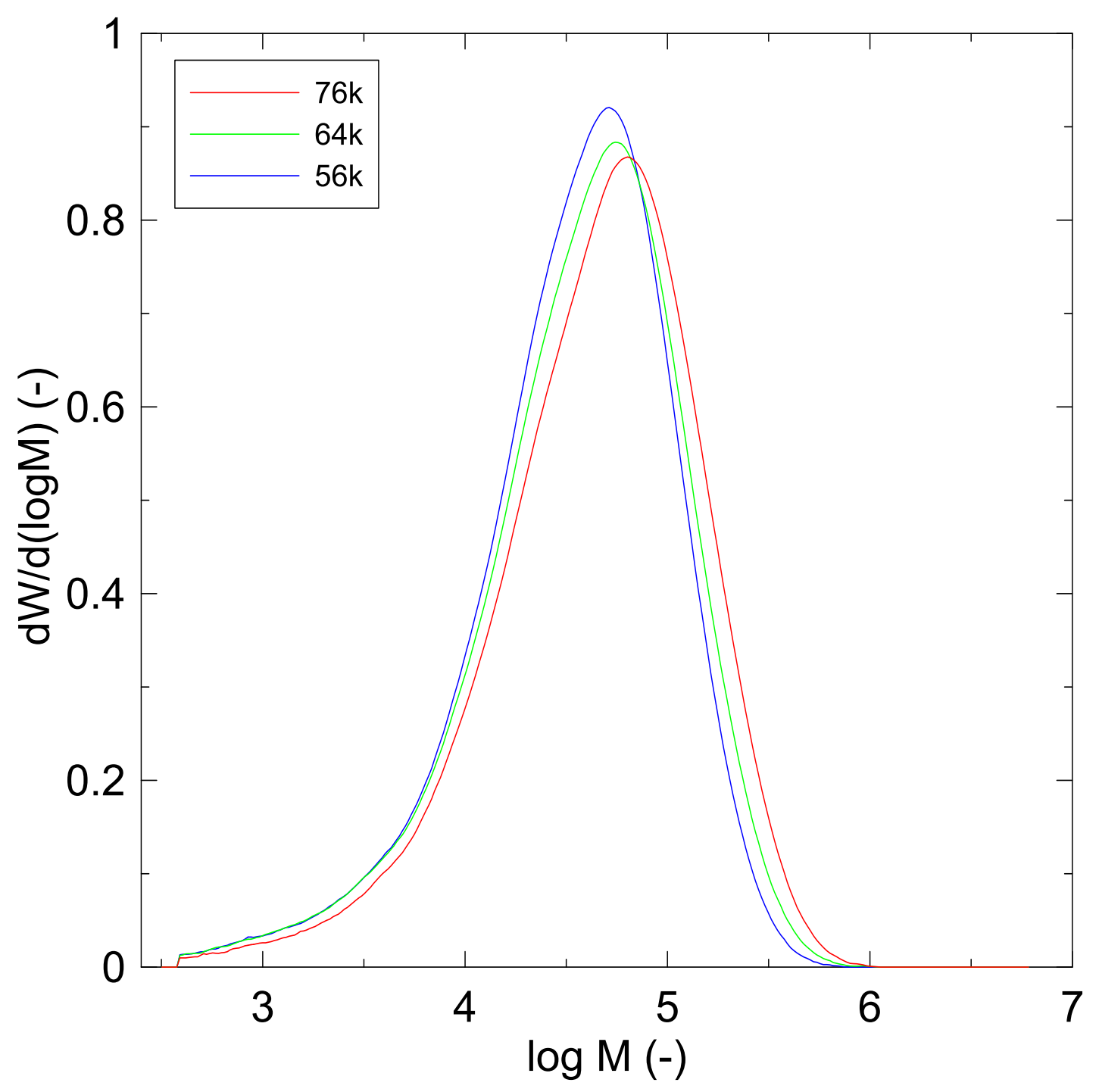

Figure 4. Molecular weight distribution (MWD) curves for all investigated linear isotactic melt blown polypropylenes (processed samples, i.e. high shear rate extrudates). 

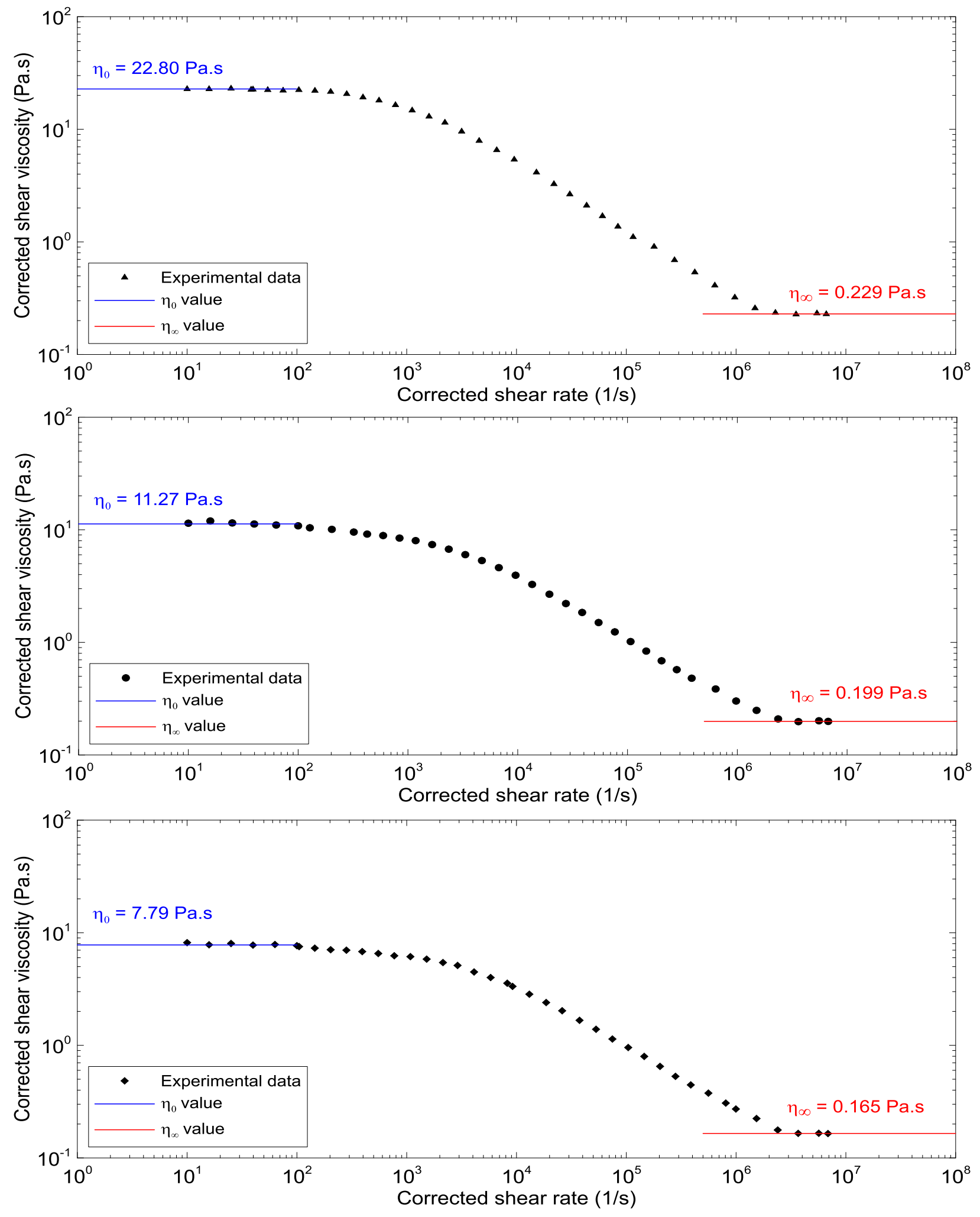

Figure 5. Deformation rate dependent shear viscosity data for linear isotactic PP Borflow 76k (top), 64k (middle) and 56k (bottom) samples at $230{ }^{\circ} \mathrm{C}$. 


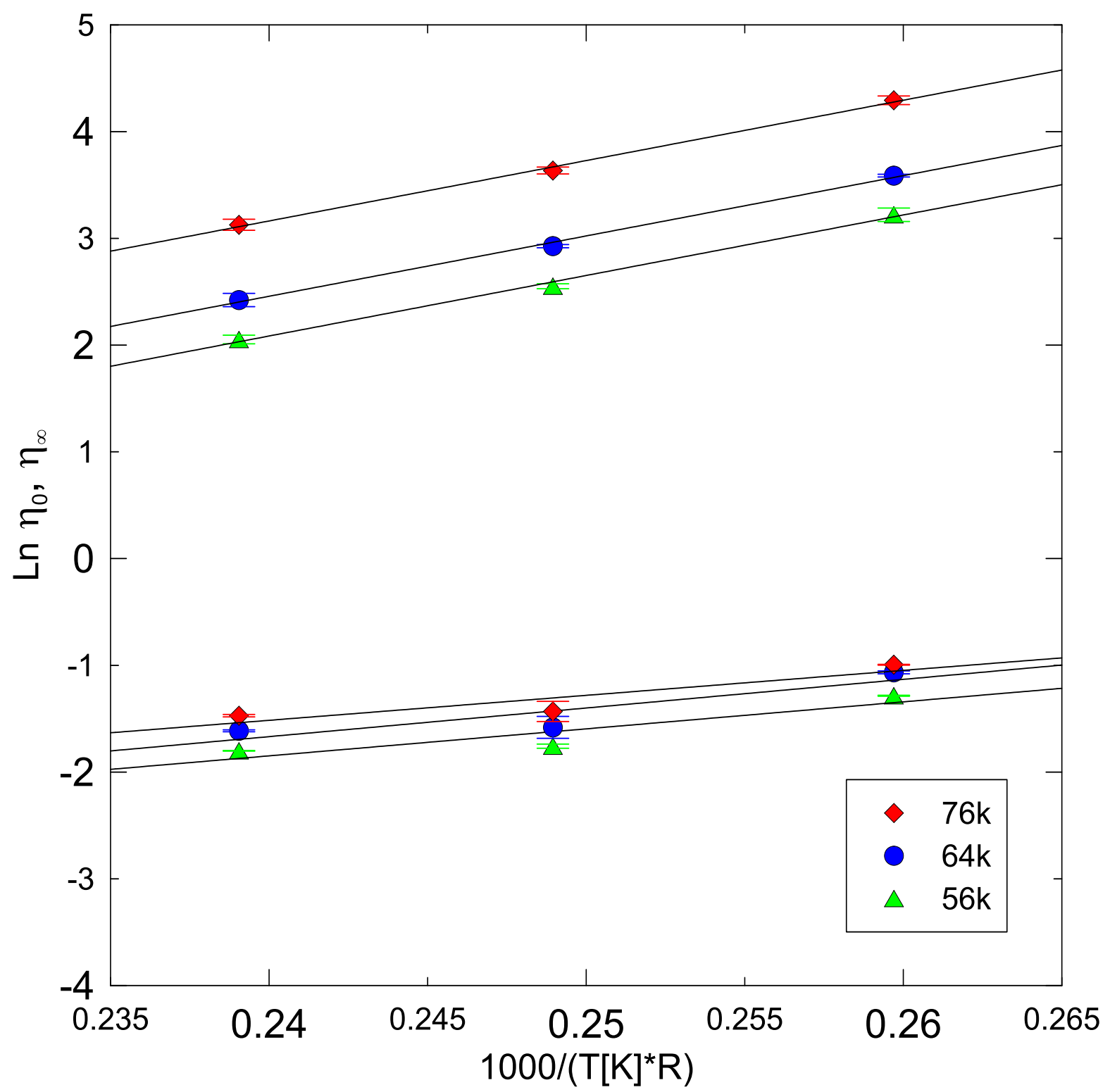

Figure 6. Arrhenius plot for $76 \mathrm{k}, 64 \mathrm{k}$ and $56 \mathrm{k}$ polypropylene melts considering $\eta_{0}$ (top) and $\eta_{\infty}$ (bottom). 


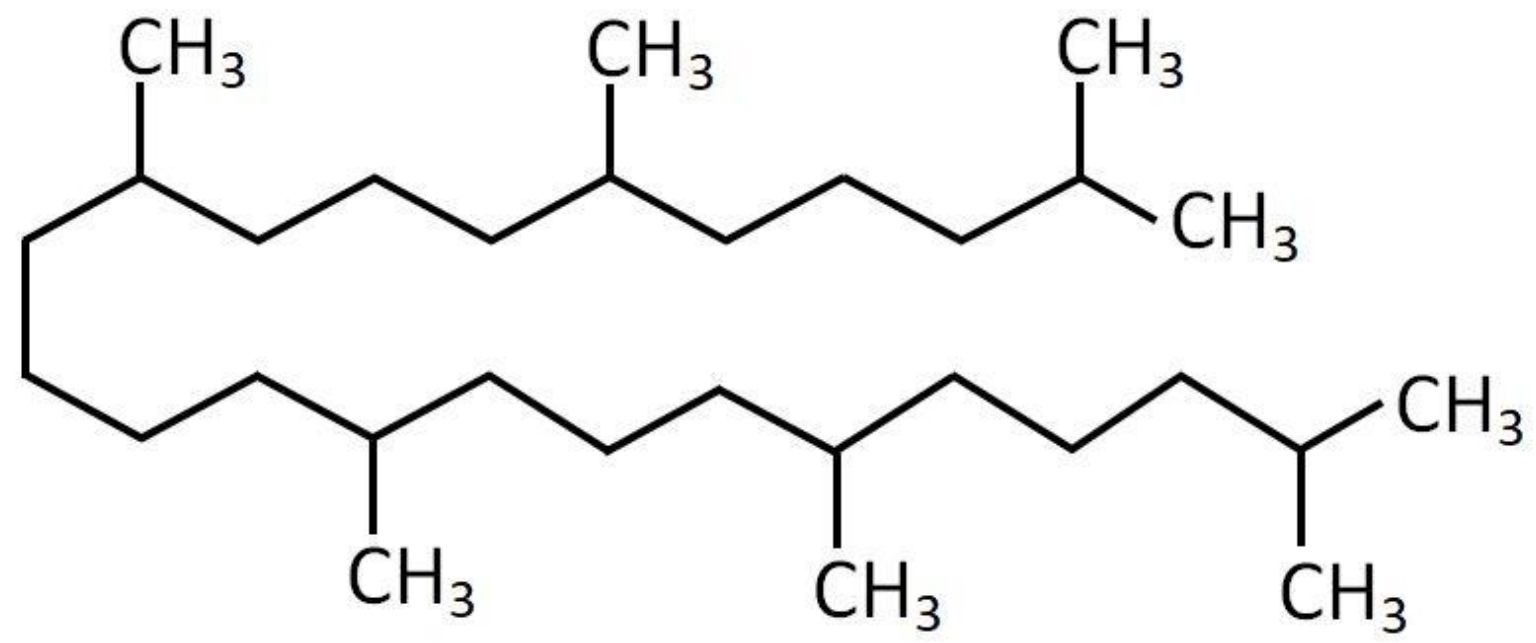

Figure 7. Chemical structure of Squalane $\left(\mathrm{C}_{30} \mathrm{H}_{62} ; 2,6,10,15,19,23\right.$-hexamethyltetracosane $)$. 


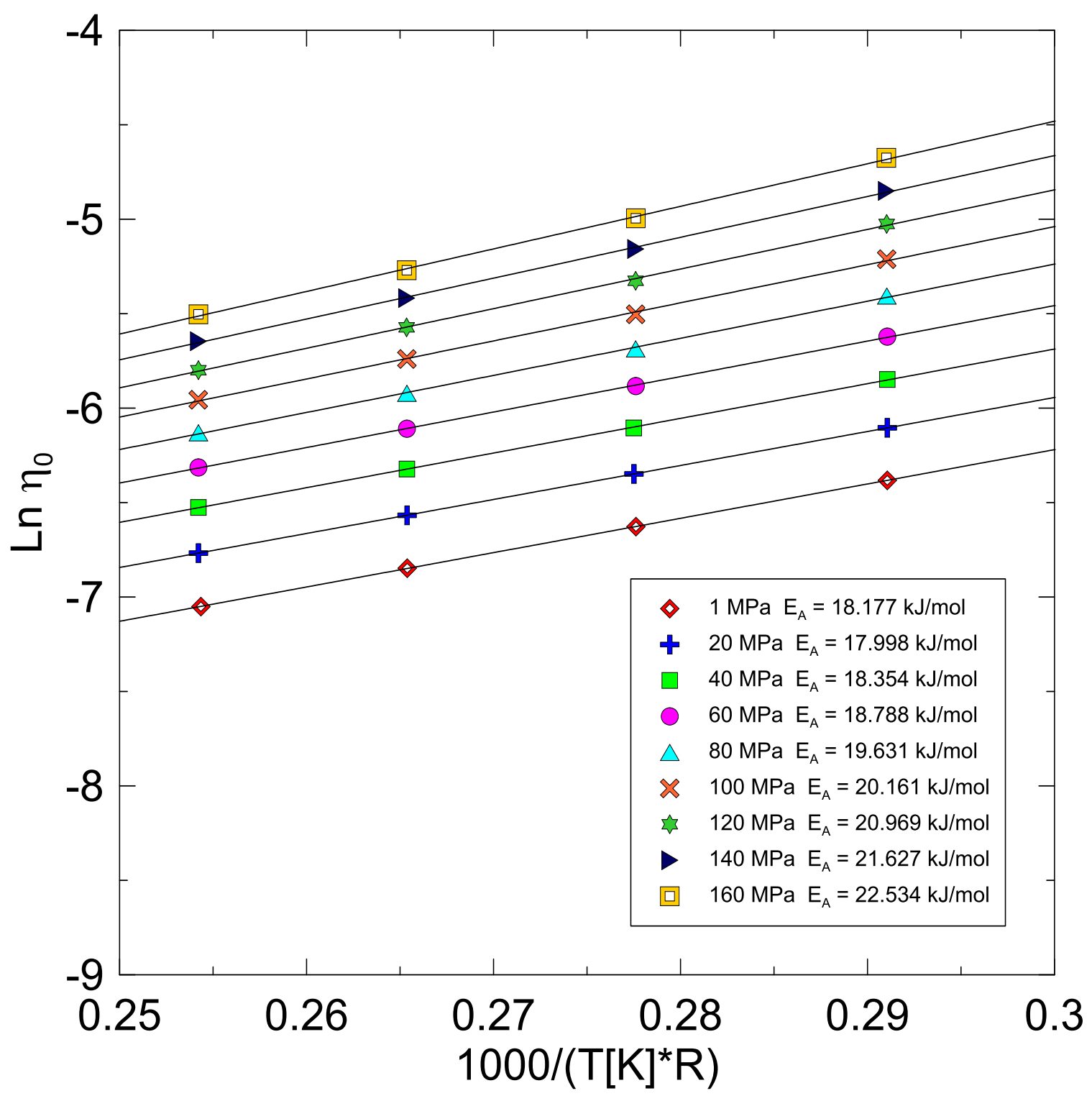

Figure 8. Arrhenius plot for Squalane (experimental data are taken from [28]). 

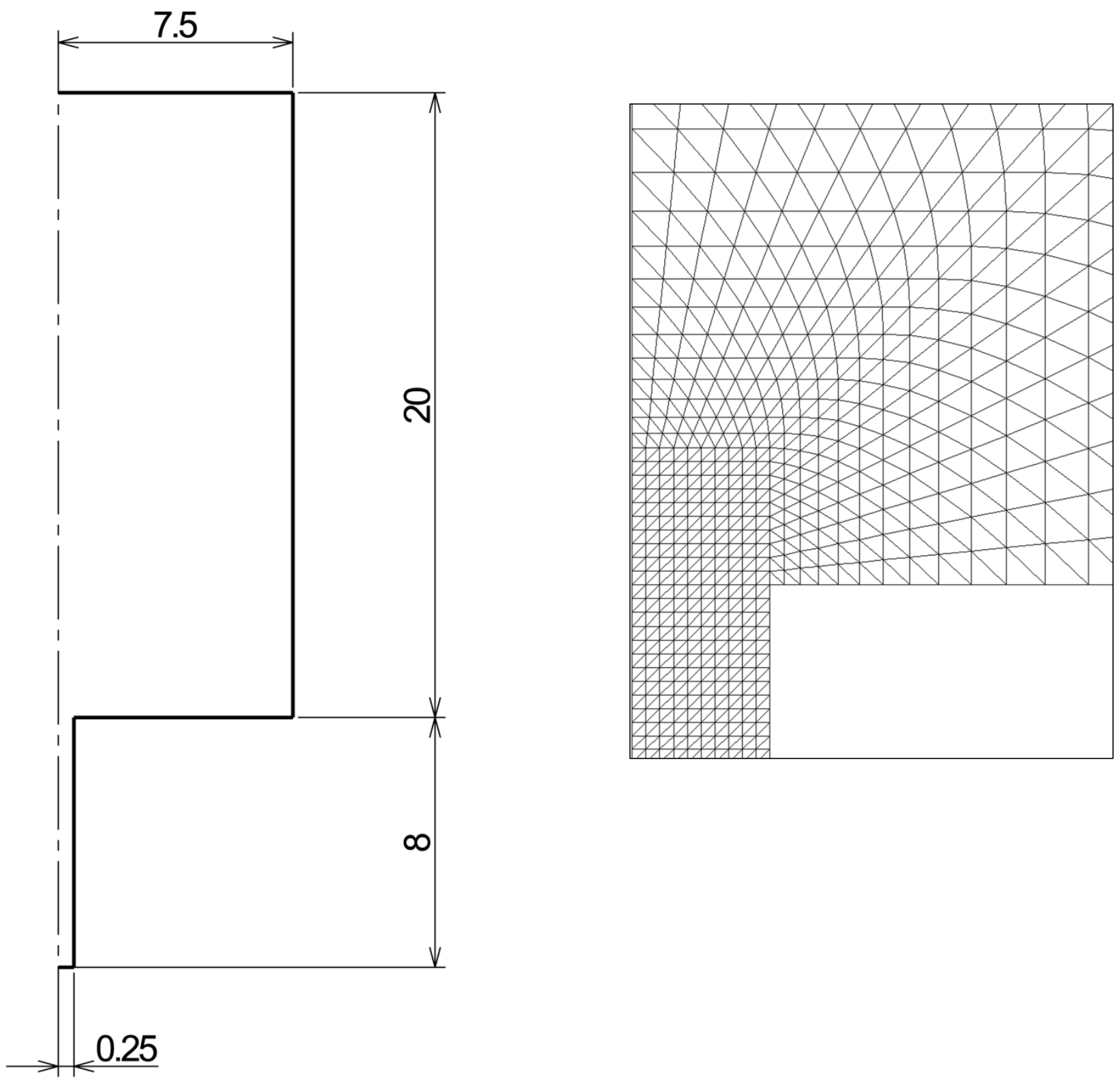

Figure 9. Geometrical sketch of simulated capillary die (left) and detail view of utilized triangular mesh at the entrance region (right). 


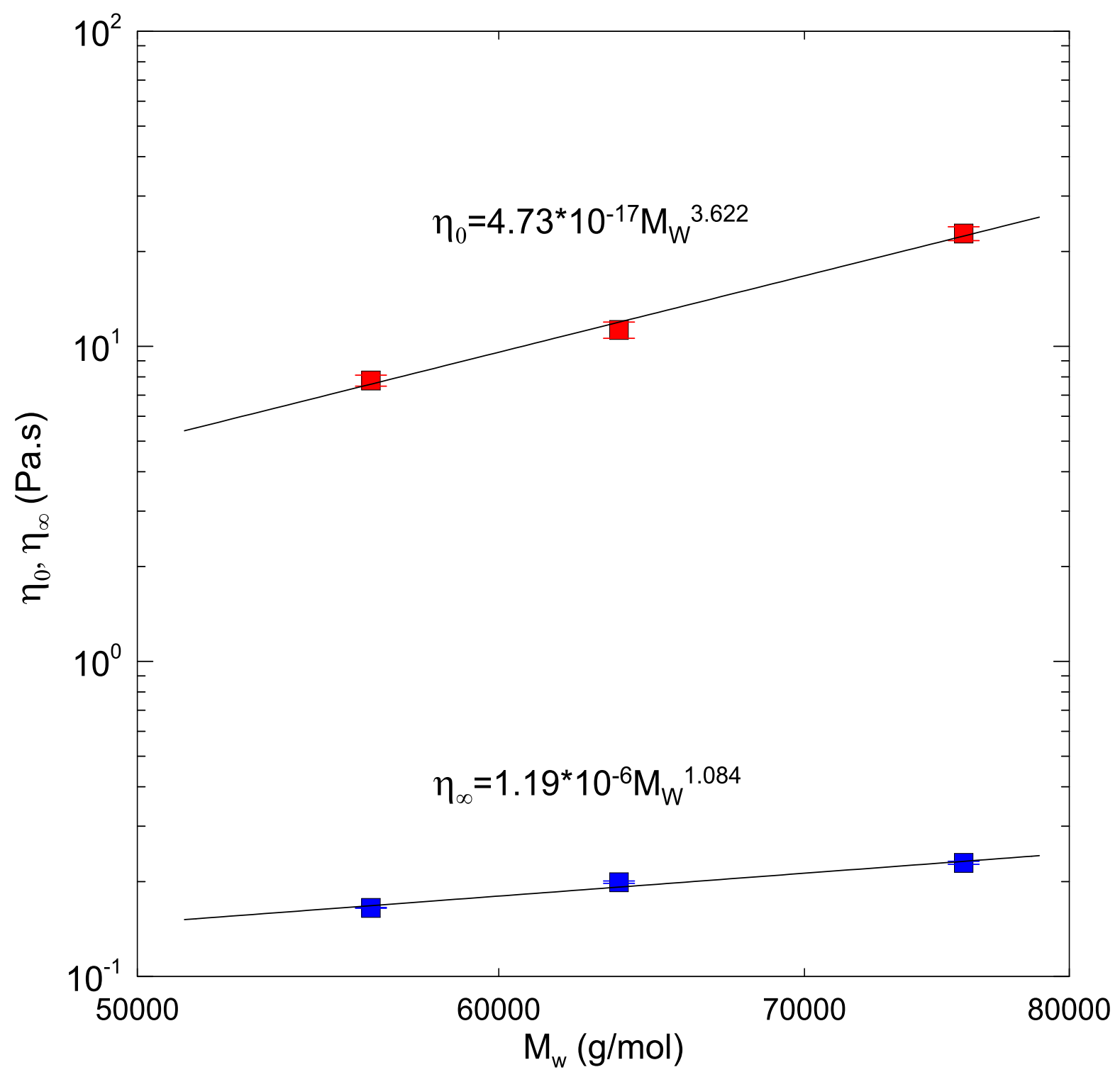

Figure 10. Effect of weight average molecular weight, $M_{w}$, on zero shear viscosity, $\eta_{0}$ (top), and secondary Newtonian viscosity, $\eta_{\infty}$ (bottom) for polypropylene melts at $230{ }^{\circ} \mathrm{C}$. 

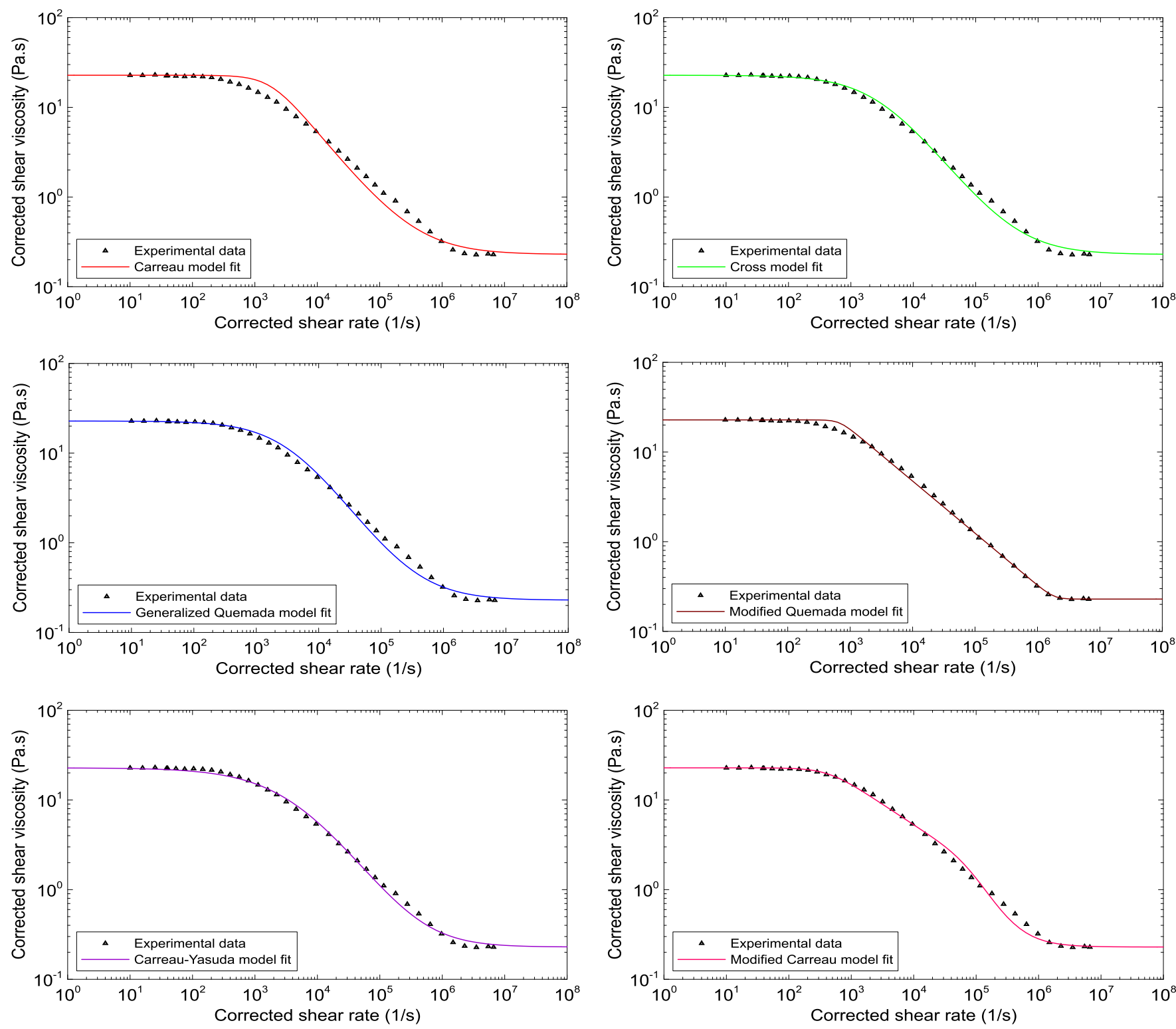

Figure 11. Comparison between experimentally determined shear viscosity data and model predictions for linear isotactic PP Borflow 76k sample at $230{ }^{\circ} \mathrm{C}$ and fixed $\eta_{0}$ and $\eta_{\infty}$ parameters. 

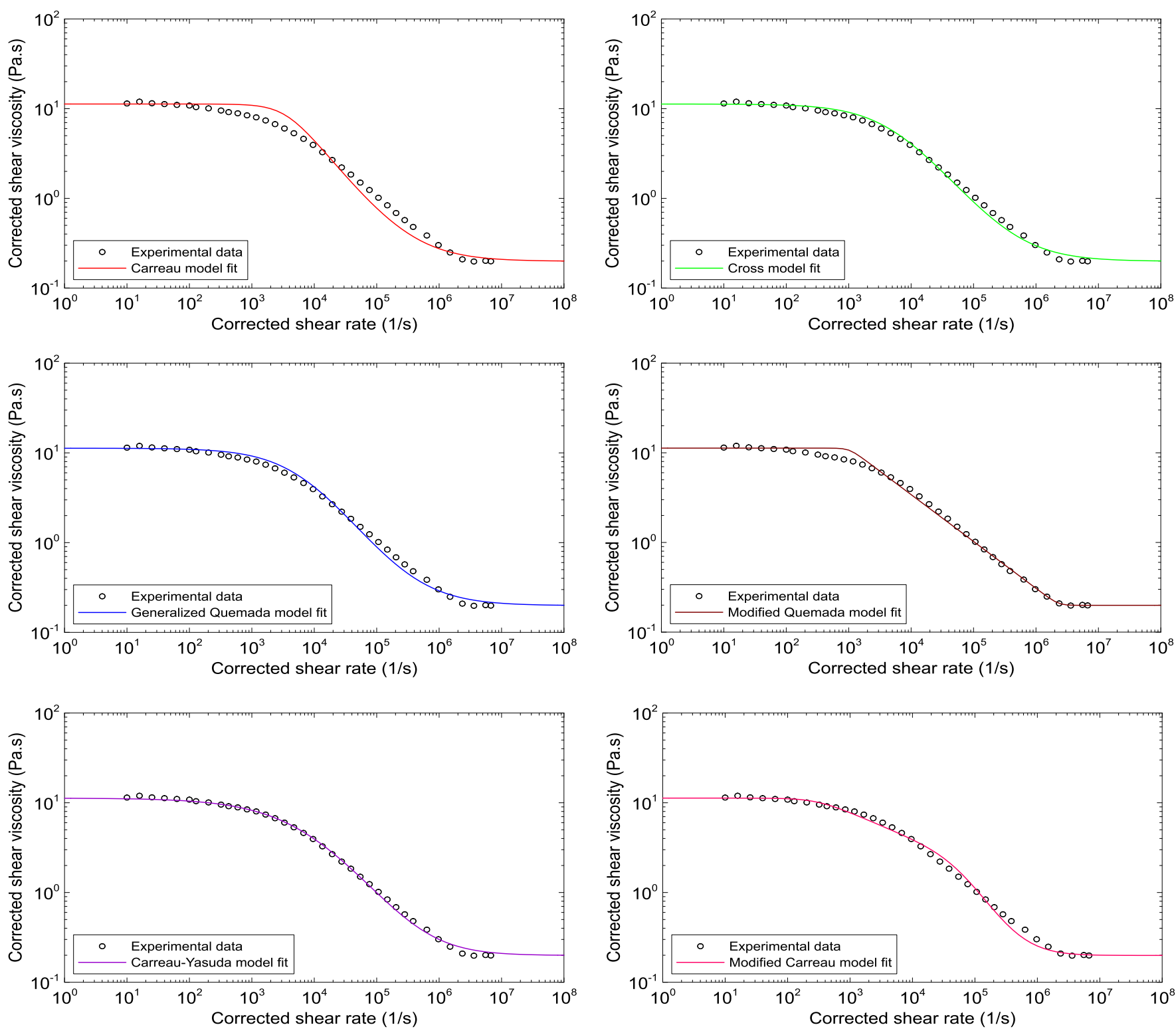

Figure 12. Comparison between experimentally determined shear viscosity data and model predictions for linear isotactic PP Borflow 64k sample at $230{ }^{\circ} \mathrm{C}$ and fixed $\eta_{0}$ and $\eta_{\infty}$ parameters. 

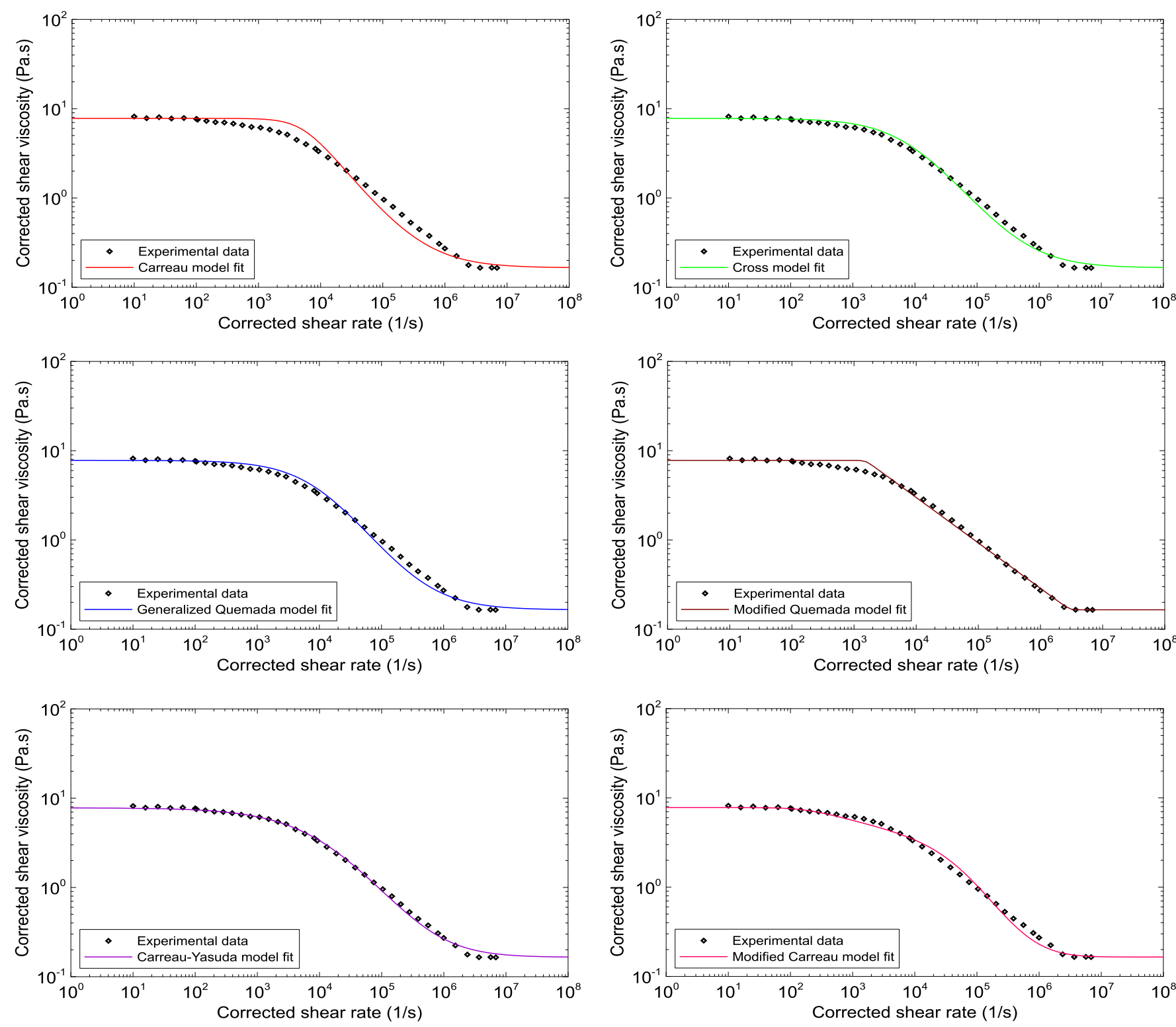

Figure 13. Comparison between experimentally determined shear viscosity data and model predictions for linear isotactic PP Borflow 56k sample at $230{ }^{\circ} \mathrm{C}$ and fixed $\eta_{0}$ and $\eta_{\infty}$ parameters. 